\title{
Estudo de Caso: o Centro de Suporte da Empresa X - Aplicação de técnicas estatísticas para apoio à gestão de serviços
}

\author{
Luiz Henrique Oliveira Ferreira, Regina Serrão Lanzillotti
}

Instituto de Matemática e Estatística- Programa de Pós-Graduação em Ciências Computacionais - Universidade do Estado do Rio de Janeiro (UERJ)

Luiz.henriquede-done.com, reginalanzillottidterra.com.br

\begin{abstract}
Customer satisfaction is a goal to any IT Service Provider and in that matter a rightsized Support Center has a key role. This paper presents a case study based on real data coming from a real Support Center, using statistical techniques to figure out the typical user demand, providing to its managers info \& tools to recognize tendencies and seasonal movements. Performing Exploratory Data Analysis and Time Series Analysis, annual and monthly ticket distributions were assessed in order to find out the typical ones; once that was accomplished, the study delved into typical daily demand distributions, aiming to help managers in human resources allocation, for instance.
\end{abstract}

Resumo. A satisfação dos seus clientes é um dos objetivos fundamentais de um prestador de serviços de TI e neste aspecto o atendimento de suporte tem papel de destaque. Este artigo faz um estudo de caso sobre os dados de atendimento de um centro de suporte real, com o uso de técnicas estatísticas, para caracterizar e tipificar a demanda dos clientes, gerando informações de que os gestores podem se valer para lidar com ela e reconhecer as tendências e movimentos sazonais. Conduzindo uma análise exploratória de dados e análise das séries temporais, foram avaliadas as frequências de chamados por períodos (anual e mensal), as características das distribuições e a curva de demanda de um dia típico para orientar a alocação de recursos técnicos para atendimento

\section{Introdução}

\subsection{Apresentação}

A empresa $\mathrm{X}$ era um fabricante global de equipamentos de informática e redes e, em certos mercados, atuava também na prestação de serviços de suporte para os clientes consumidores de seus produtos. No Brasil, a empresa X mantinha um Centro de Suporte voltado para o atendimento dos usuários corporativos. Nele estavam alocados técnicos, analistas e engenheiros aos quais eram direcionados os chamados com base na complexidade de cada tarefa.

De maneira simplificada, as demandas encaminhadas ao Centro de Suporte eram classificadas em chamados do Tipo 1 (serviços de instalação, upgrades e melhorias de configuração, tratados de forma planejada) e do Tipo 2 (restabelecimento do status operacional, em virtude de falhas no funcionamento dos equipamentos ou serviços associados). 
Assim como na maioria dos serviços similares, quanto mais chamados atendidos, maior era a receita do Centro de Suporte. A quantidade de chamados do Tipo 1 podia sofrer influência de campanhas de venda ou ações promocionais, que fomentavam a demanda por novas instalações ou melhorias operacionais; já os chamados do Tipo 2 estavam sujeitos a circunstâncias essencialmente aleatórias.

Este artigo ajuda a resolver o desafio de oferecer aos gestores da empresa $\mathrm{X}$ instrumentos para equilibrar seus recursos (principalmente técnicos e especialistas) com a demanda dos clientes. Como qualquer outra empresa, ela tinha especial interesse em maximizar seus lucros, então desejava o menor custo possível para seu Centro de Suporte. Na outra ponta da cadeia de serviços, os clientes desejavam o atendimento imediato de suas demandas, sem se importar com o ônus que isto poderia representar para a empresa X. Esta problemática pode ser vista também em (FUKUNAGA, et al., 2002), (SICA \& RIBEIRO, 2010) e (YONAMINE, 2006); esses trabalhos têm foco em call centers, mas há semelhança entre estes e o Centro de Suporte estudado.

O foco da análise recaiu sobre os chamados do Tipo 1, mas as técnicas e métodos aqui descritos podem ser replicados para os demais chamados. Ressalte-se que a limitaçção de recursos disponíveis na empresa $X$ orientou a escolha feita neste trabalho, de usar apenas métodos clássicos (SPIEGEL, 1972) (ALVES, et al., 2009) (BOUZADA, 2012) e ferramentas de domínio geral, especialmente o MS Excel.

\subsection{Objetivos}

Este artigo visa identificar os padrões de demanda do Centro de Suporte para que os recursos técnicos sejam alocados de forma adequada. Os dados coletados foram usados para tentar modelar a demanda, projetar tendências e sazonalidade. Busca-se caracterizar tipicidade:

(1) $\mathrm{Na}$ distribuição de atividades ao longo do tempo, para antecipar a demandas futuras e realizar ajustes na operação do Centro de Suporte;

(2) Na distribuição diária de atividades, para definir as escalas de trabalho.

\subsection{Abordagem, técnicas e métodos}

$\mathrm{Na}$ análise foi usado o conjunto de dados relacionados ao atendimento prestado pelo Centro de Suporte da empresa X no período de 01/11/08 até 10/11/11. Os dados foram obtidos a partir de relatórios de atendimento e representam uma amostra de $\mathbf{2 4 . 2 3 9}$ chamados, extraídos a partir de um conjunto de 39.800 chamados; a redução é devida ao expurgo de dados sem consistência ou não relacionados a serviços da empresa X.

$\mathrm{Na}$ Seção 2.1 é realizada uma análise exploratória dos dados, focando na distribuição de chamados por dia ao longo de todo o período da amostra. Os dados foram também estratificados em períodos de um ano. Medidas de posição (média, moda e mediana) e de dispersão (desvio padrão, variância, coeficiente de variação etc) foram usadas para caracterizar as distribuições, mas a grande variabilidade dos dados não ensejou aderência à distribuição normal e apontou a necessidade de uma análise da série temporal, o que é feito na Seção 2.2.

A análise da série seguiu o método clássico para a determinação dos componentes de Tendência (T), Sazonalidade (S), Cíclicos (C) e Irregulares (I) (SPIEGEL, 1972, pp. 468-502) (REIS, 2013, pp. 1-25 [cap. 4]). Embora tenham sido 
feitos ensaios tanto com o modelo multiplicativo $(Y=T S C I)$ quanto com o modelo aditivo $(Y=T+S+C+I)$ de decomposição da série, o primeiro se mostrou mais adequado pela avaliação de acuracidade para a série (REIS, 2013) e é o que foi usado neste trabalho. O modelo mais acurado é aquele cujos indicadores de erro têm menores valores. Os seguintes indicadores foram calculados:

EAM (Erro absoluto médio):

$$
E A M=\frac{1}{N} \sum_{t=1}^{N}\left|e_{t}\right|
$$

EPM (Erro percentual médio):

$$
E A M=\frac{1}{N} \sum_{t=1}^{N}\left[\frac{e_{t}}{Y_{t}} \times 100\right]
$$

EQM (Erro quadrático médio):

$$
E Q M=\frac{1}{N} \sum_{t=1}^{N} e_{t}{ }^{2}
$$

EPAM (Erro percentual absoluto médio):

$$
E P A M=\frac{1}{N} \sum_{t=1}^{N}\left|\frac{e_{t}}{Y_{t}} \times 100\right|
$$

Sendo $e_{t}=Y_{o}-Y_{t}$, ou seja, no momento $t$, o erro é a diferença entre o valor original da série e o valor obtido quando se recompõe a série com as componentes $T, S$, $C$ e $I$ obtidas.

Para a determinação da tendência foram aplicadas na Seção 2.2.1 várias técnicas de ajuste de curvas mostradas na Tabela 1.

Tabela 1. Métodos de ajuste de curva usados

\begin{tabular}{|l|l|}
\hline Tendência/Equação & Método de cálculo \\
\hline $\begin{array}{l}\text { Linear } \\
(y=a+b t)\end{array}$ & Os termos $a$ e $b$ foram determinados pelo método dos mínimos quadrados \\
\hline $\begin{array}{l}\text { Quadrática } \\
\left(y=a+b t+c t^{2}\right)\end{array}$ & $\begin{array}{l}\text { Os termos } a, b \text { e } c \text { foram determinados determinados pelo método dos } \\
\text { mínimos quadrados }\end{array}$ \\
\hline $\begin{array}{l}\text { Exponencial } \\
\left(y=a b^{t}\right)\end{array}$ & $\begin{array}{l}\text { A equação } y=a b^{t} \text { foi logaritmizada em ln } y=l n \text { l }+t(l n \text { b), então foi } \\
\text { aplicado o método dos mínimos quadrados }\end{array}$ \\
\hline $\begin{array}{l}\text { Média móvel (MM) } \\
\text { centrada de } 12 \text { meses }\end{array}$ & $\begin{array}{l}\text { O cálculo da média móvel é amplamente discutido em (SPIEGEL, 1972) } \\
\text { (REIS, 2013). Resta comentar que o uso da média móvel tem a deficiência } \\
\text { de não produzir valores na linha de tendência para o início o o fim da série, e } \\
\text { esta situação pode ser prejudicial quando da necessidade de se obter valores } \\
\text { de previsão após o período coletado. }\end{array}$ \\
\hline $\begin{array}{l}\text { Média móvel } \\
\text { exponencialmente } \\
\text { ponderada (MMEP) } \\
\left(y_{t}=w y_{o}+(1-w) y_{t-1},\right. \\
0<w<1)\end{array}$ & $\begin{array}{l}\text { (REIS, 2013) ensina que w é o peso aplicado ao ajuste exponencial e } y_{o} \text { e } y_{t}, \\
\text { respectivamente, o valor observado e o valor estimado pela curva no tempo } \\
\text { t. Este método também é chamado de suavização exponencial }\end{array}$ \\
\hline
\end{tabular}

Os índices de sazonalidade foram calculados na Seção 2.2.2, usando os métodos do percentual mensal, das médias móveis e dos elos relativos.

Para o método dos percentuais mensais, precisou ser calculada a relação entre a 
quantidade de chamados do mês e a média do período anual, $R=\frac{Y_{\mathrm{t}}}{\left(\frac{2 Y_{\mathrm{t}} \text { (perr }}{12}\right)}$, onde $Y_{t}$ é o valor da série no mês $t$ e $\Sigma Y_{t}\left(\right.$ per) o somatório dos $Y_{t}$ do período anual a que $t$ pertence. Para o método das médias móveis, foi calculada a relação entre a quantidade de chamados do mês e o valor da média móvel em $t, R=\frac{Y_{t}}{M M_{t}}$, com $M M_{t}$ sendo igual à média móvel do momento $t$. Finalmente, para o método dos elos relativos, foi calculada a relação entre a quantidade de chamados do mês e a do mês anterior, $R=\frac{Y_{t}}{Y_{t-1}}$. Cada $m$ $=t \bmod 12$, corresponde a um mesmo mês do ano (janeiro, fevereiro etc). Os índices de sazonalidade para cada mês $m$ foram obtidos pela média dos quocientes $R$ desse mês. Em alguns casos, as médias precisaram ser ajustadas para que a soma dos índices calculados fosse compatível com o período anual (1200\%), conforme descrito em (SPIEGEL, 1972, p. 488).

A escolha sobre qual conjunto de índices de sazonalidade seria usado na continuidade do trabalho envolveu a avaliação dos coeficientes de variação desses índices em cada mês $m$ quando comparados aos quocientes dos meses $t=12 \mathrm{~m}$.

Os dados da série foram desestacionalizados na Seção 2.2.3. A desestacionalização da série $\left(\frac{Y}{S}=T C I\right)$ permite remover dela as componentes sazonais, cujos índices foram calculados na Seção 2.2.2.

O estudo das variações cíclicas e irregulares da série é mostrado na Seção2.2.4. Para este estudo, parte-se da série com os dados desestacionalizados, removendo-se, então, a tendência. Foram feitos ensaios de remoção de tendência com as várias curvas $T$ obtidas pelos métodos citados na Tabela 1. Em função dos dados disponíveis, que se espalham em apenas três anos, não cabe supor a existência de uma componente cíclica na decomposição da série, já que os ciclos normalmente se revelam no longo prazo e apresentam alguma periodicidade (embora nem sempre tomada em tempos iguais) (SPIEGEL, 1972). Portanto, uma vez removida a tendência, os modelos trabalhados revelaram as variações irregulares, apesar das referências a $C I$.

A Seção 2.2.5 ajusta o patamar da série de chamados, revelando uma nova série que é estudada na Seção 2.2.6. Uma análise qualitativa dos achados é mostrada na Seção 2.3.

Toda a Seção 2.4 trata de avaliar a curva de demanda de trabalho diária, com o objetivo de determinar as necessidades de pessoal. Vários autores abordam a questão da montagem de escalas de trabalho, como (ROBBINS \& HARRISON, 2010), (MUSLIU, et al., 2004), (MENDES, et al., 2006), (GÄRTNER, et al., 2001) e (BARBOSA, 2010). Esses trabalhos são bastante elaborados, com técnicas e métodos que dificilmente seriam aplicados na empresa X (consideradas a ausência de gestores capacitados e a restrição de recursos). Comum entre aqueles trabalhos é o fato de partirem de uma demanda já determinada para produzir as escalas; aqui procuramos avaliar os dados reais do Centro de Suporte para determiná-la. 


\section{Aplicação}

\subsection{Análise da distribuição dos chamados}

A primeira análise da distribuição de chamados por dia cobriu todo o período da amostra e se mostrou bastante longe da distribuição normal (Figura 1). Chamam a atenção a moda de valor baixo (comparada à média e à mediana) e a pequena quantidade de ocorrências esparsamente distribuídas a partir da frequência acumulada de $92,3 \%$.

Dos 50 dias em que ocorreram os valores iguais à moda, 45 referem-se a sábados e domingos e outros 3 a feriados ou pontos facultativos. Com isto, duas populações ficaram caracterizadas: a dos dias úteis (seg, ter, qua, qui, sex) e a dos dias não úteis $(\mathrm{dnu}=\mathrm{sab}$, dom e feriados), cuja distribuição percentual é mostrada na Figura 2 (esta situação já era percebida no Centro de Suporte e a alocação de recursos para cobertura de dias não úteis não guardava semelhança com a dos dias úteis).

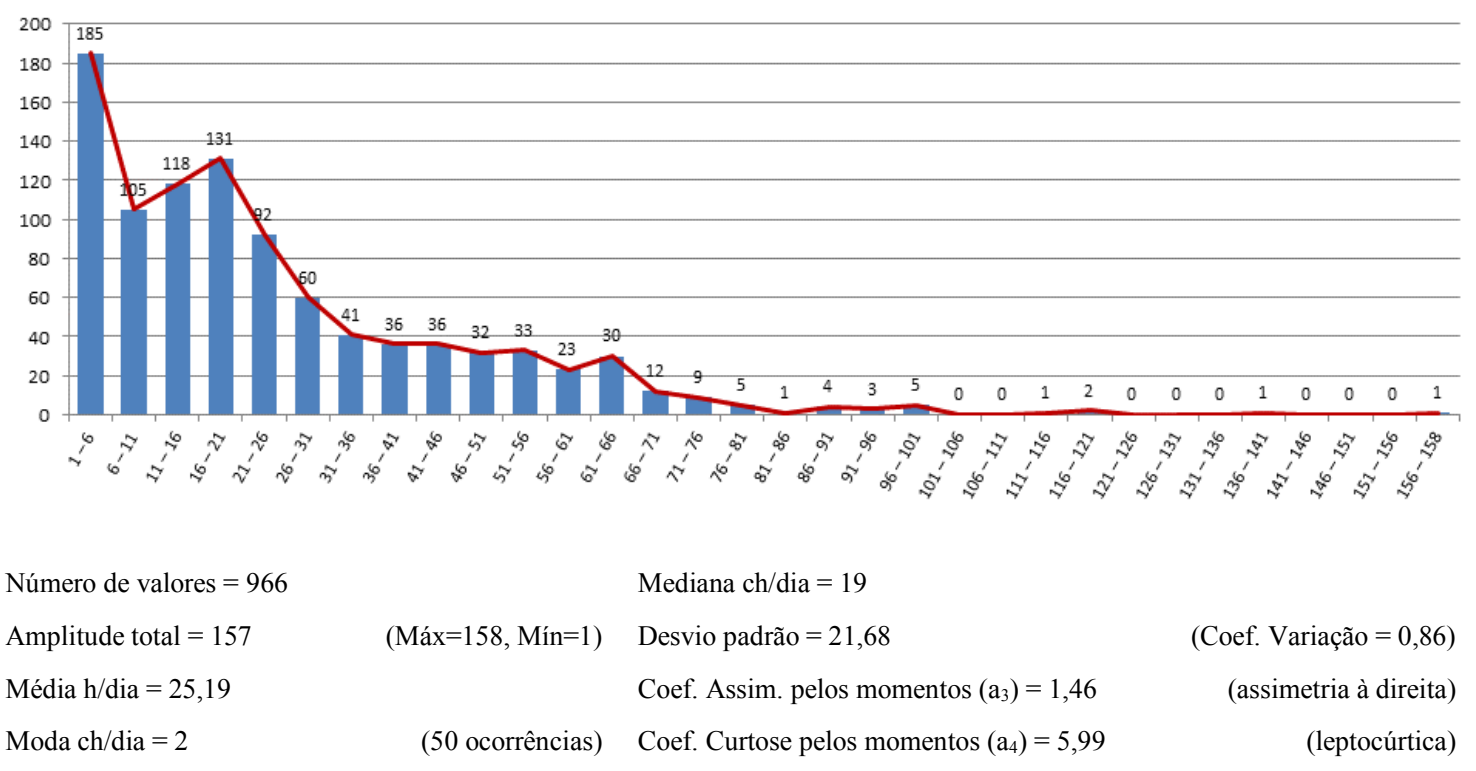

Figura 1. Distribuição de frequências (chamados por dia)

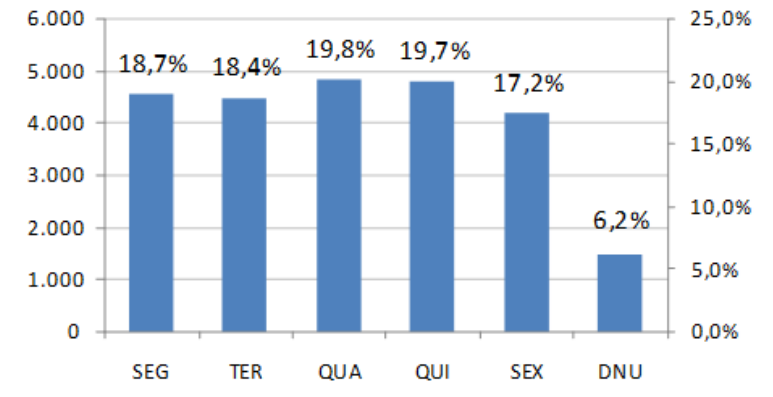

Figura 2. Distribuição de chamados por dia da semana

A população mais expressiva da amostra representa cerca de $94 \%$ dos dados (ocorrências em dias úteis). A outra população foi descartada da análise.

No outro extremo da distribuição de frequências há 51 ocorrências de valores iguais ou superiores a 66 chamados por dia, todas no período de um ano a partir de 
Nov/08 (ver Tabela 2), o que sugere fortemente outra população na amostra coletada. Os dados foram então estratificados em períodos de um ano, buscando similaridades ou padrões em cada período, de novembro de um dado ano até outubro do ano seguinte. $\mathrm{O}$ mês de novembro de 2011 foi descartado (os dados coletados são insuficientes para caracterizá-lo, pois só vão até o dia 10, tampouco ele seria bastante para um novo período anual).

Tabela 2. Distribuição dos dias com quantidade de chamados $\geq 66$

\begin{tabular}{|c|c|c|c|c|c|c|c|c|c|c|c|}
\hline Ano & \multicolumn{2}{|c|}{2008} & \multicolumn{8}{|c|}{2009} & \multirow{3}{*}{$\begin{array}{c}\text { Total geral } \\
51\end{array}$} \\
\hline Mês & nov & dez & fev & mar & $a b r$ & mai & jun & jul & ago & set & \\
\hline Total & 4 & 3 & 1 & 11 & 4 & 7 & 5 & 6 & 7 & 3 & \\
\hline
\end{tabular}

O resultado dessa estratificação aparece nas Figuras 3,4 e 5. As distribuições se aproximam mais da distribuição normal, mas verifica-se ainda assimetria à direita em todas elas e, tal como na distribuição inicial, pequena quantidade de valores esparsamente distribuídos a partir das frequências acumuladas próximas a $92-93 \%$. Mesmo com o coeficiente de variação no entorno de $40 \%$ em todos os períodos, as medidas de posição para o $1^{\circ}$ período (de Nov/08 a Out/09) são consideravelmente maiores que as dos períodos seguintes. O coeficiente de curtose mostra que a concentração dos valores em torno da moda nos períodos de Nov/09 a Out/10 e Nov/10 a Out/11 é maior. Em síntese, temos um período com maior atividade e dois períodos com atividade menor e mais similar. Com isto, passamos à análise da série temporal, vista na próxima seção.

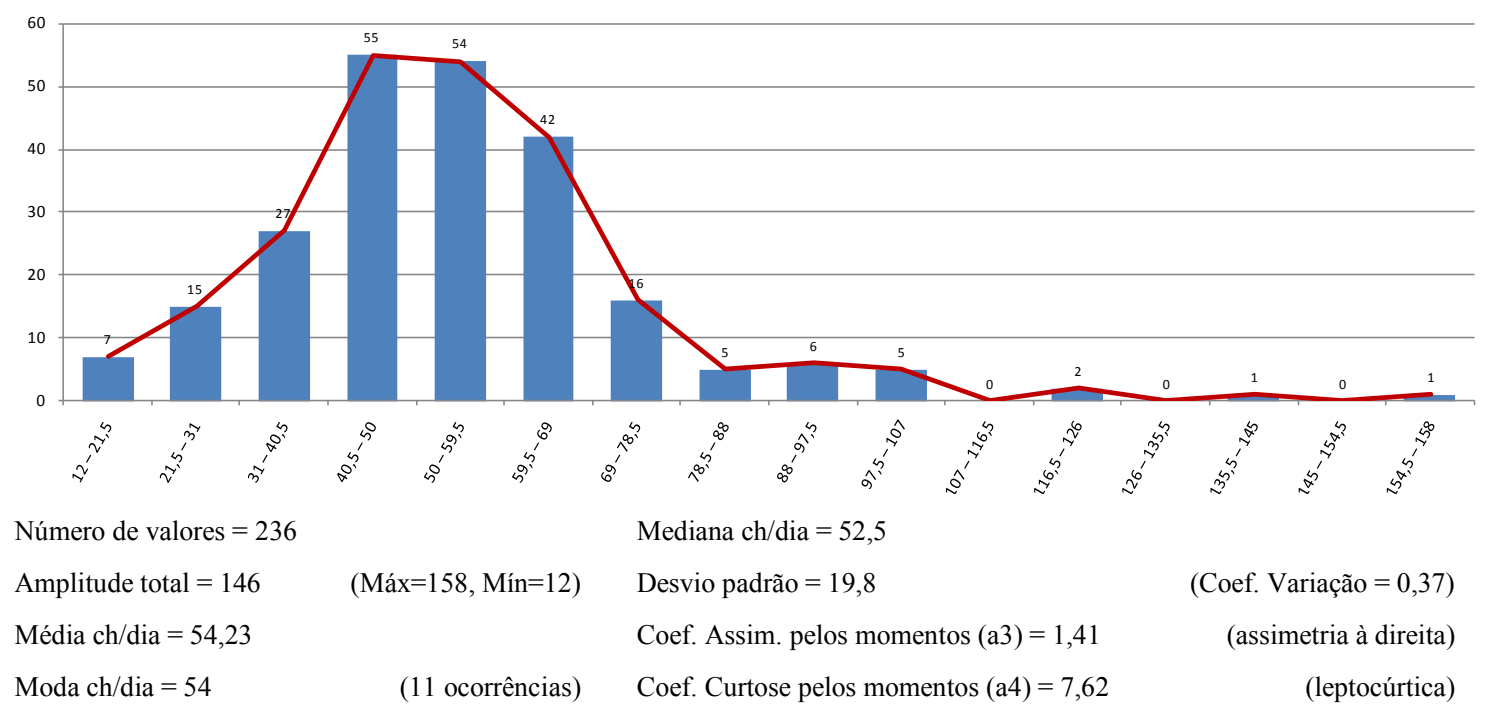

Figura 3. Distribuição de frequências (chamados por dia - Nov/08 a Out/09) 


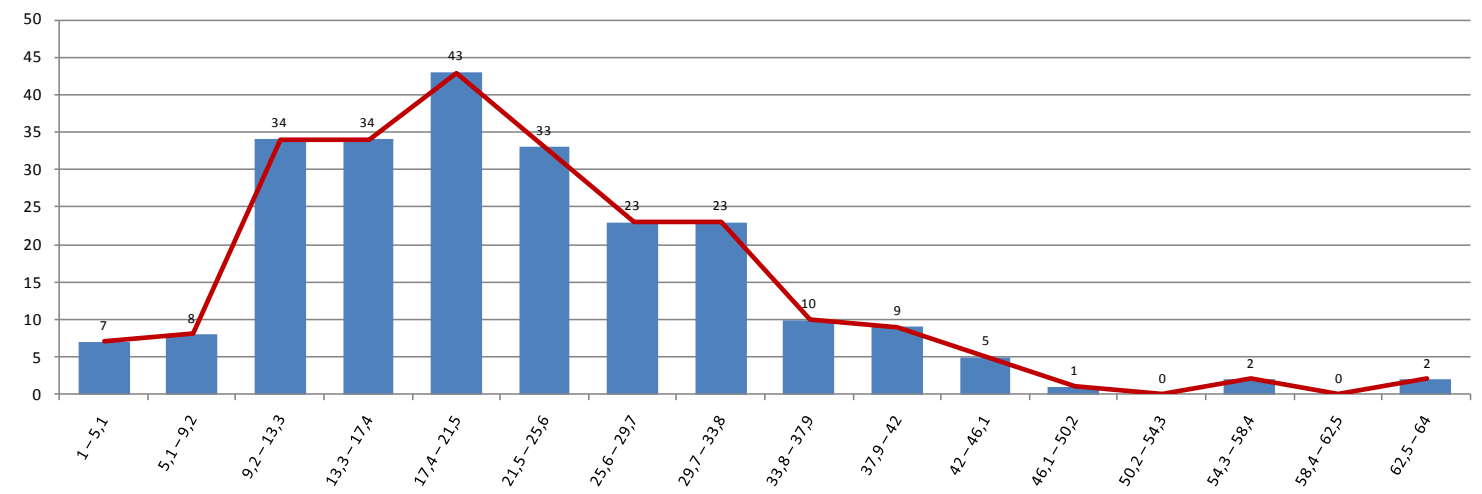

Número de valores $=234$

Mediana $\mathrm{ch} / \mathrm{dia}=21$

Amplitude total $=63$

(Máx=64, Mín=1)

Desvio padrão $=10,59$

(Coef. Variação $=0,37)$

Média $\mathrm{ch} / \mathrm{dia}=22,15$

Coef. Assim. pelos momentos $(\mathrm{a} 3)=0,93$

(assimetria à direita)

Moda $\mathrm{ch} / \mathrm{dia}=23$

(13 ocorrências)

Coef. Curtose pelos momentos (a4) $=4,56$

(leptocúrtica)

Figura 4. Distribuição de frequências (chamados por dia - Nov/09 a Out/10)

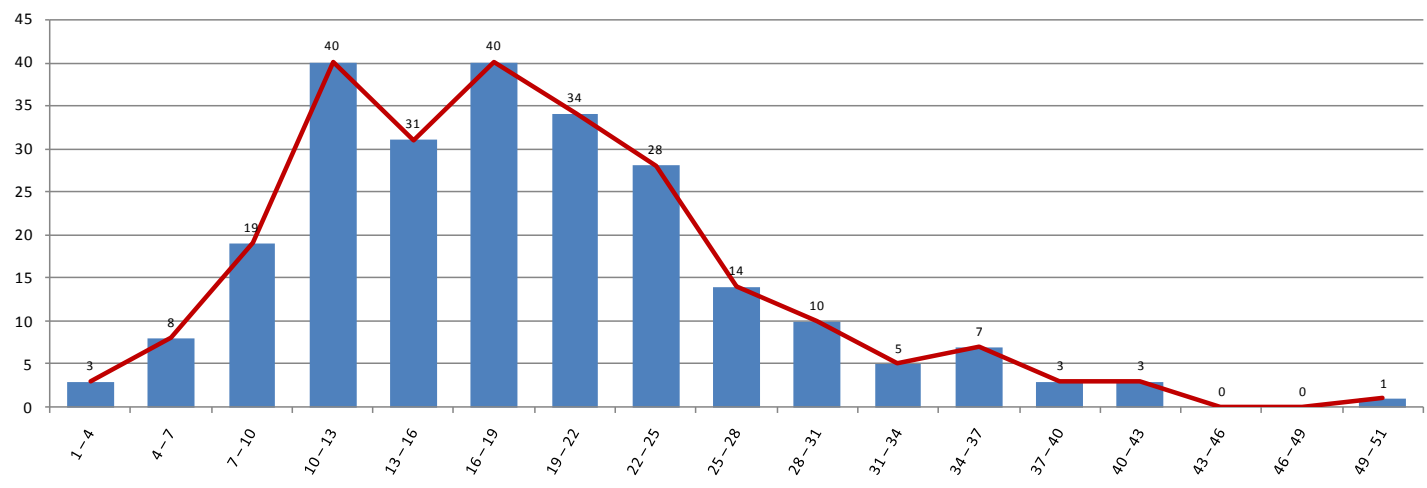

Número de valores $=246$

Amplitude total $=48$

Média $\mathrm{ch} / \mathrm{dia}=18,97$

Moda $\mathrm{ch} / \mathrm{dia}=12$

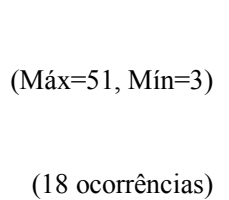

Coef. Assim. pelos momentos (a3) $=0,6$

Coef. Curtose pelos momentos $(\mathrm{a} 4)=3,73$
(Coef. Variação =0,42)

(assimetria à direita)

(leptocúrtica)

Figura 5. Distribuição de frequências (chamados por dia - Nov/10 a Out/11)

\subsection{Análise da série temporal}

Em primeiro lugar, como a contagem de dias úteis de Nov/08 a Out/11 apresentou média igual a 19,9, mediana igual a 20 e CV igual a $11.5 \%$, considera-se neste estudo que cada mês é composto de aproximadamente 20 dias úteis. Os dados da série foram organizados com períodos anuais iniciando-se em Novembro e indo até Outubro do ano posterior. A representação gráfica da série mensal relacionada à ocorrência de chamados é mostrada na Figura 6. 


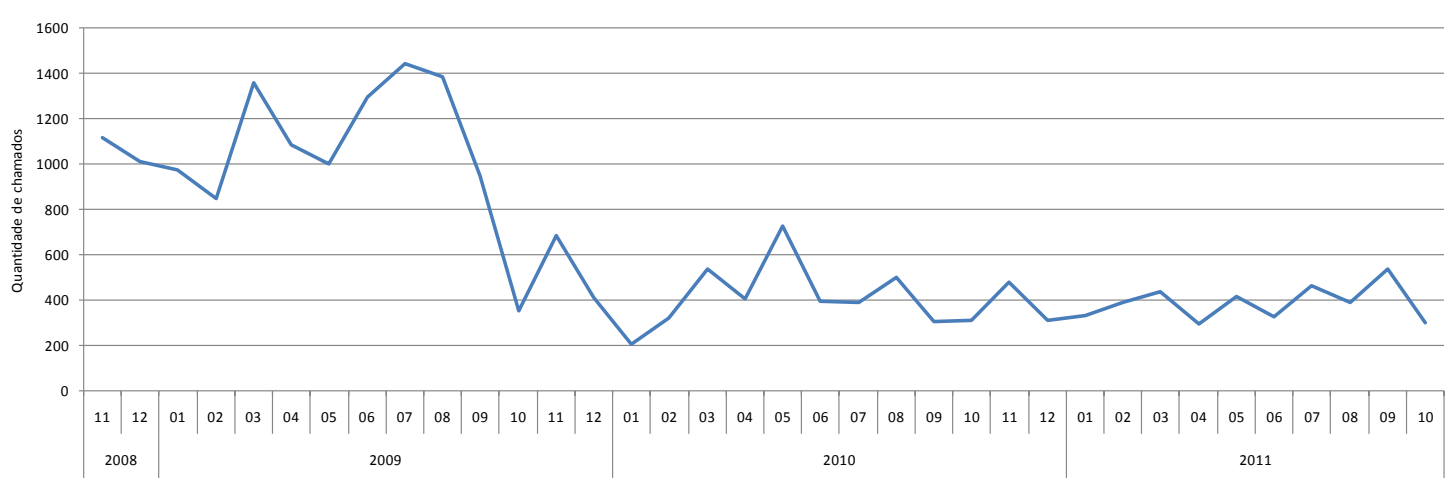

Figura 6. Quantidade de chamados por mês (Nov/08 a Out/10)

\subsubsection{Análise de Tendência - ajuste da série à curva de tendência}

Usando os métodos descritos na Tabela 1, foram feitos ensaios para ajuste da curva, cujas representações gráficas são mostradas na Figura 7 e na Figura 8.

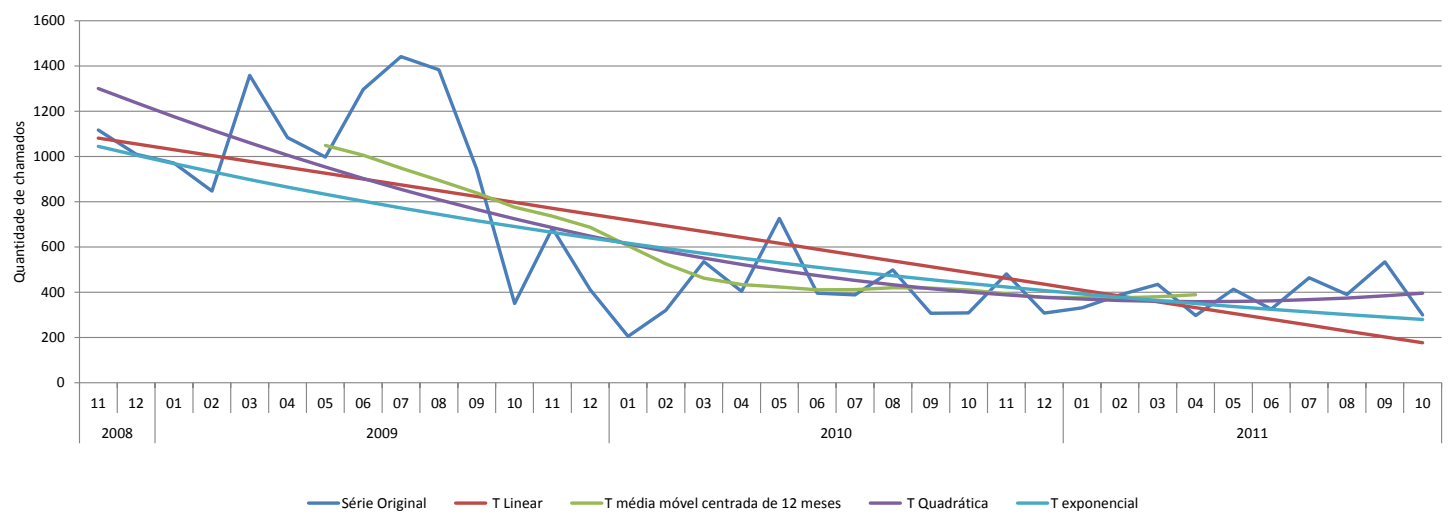

Figura 7. Ajuste de curvas (MM, linear, quadrática e exponencial) p/análise de tendência da série temporal dos chamados

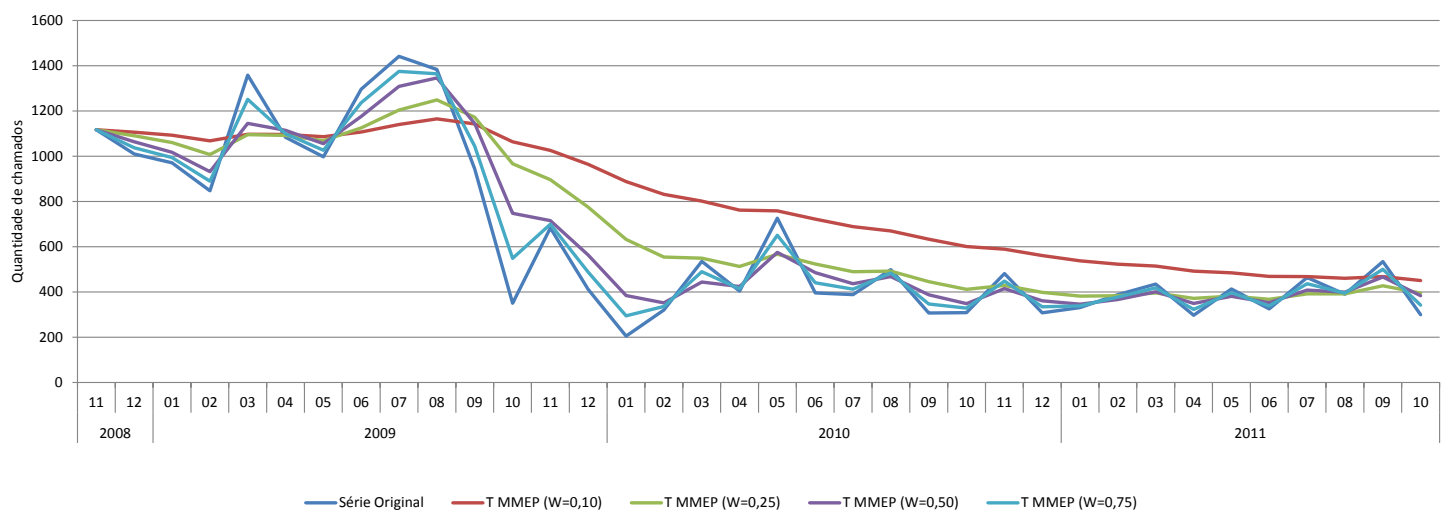

Figura 8. Ajuste de curvas (MMEP) p/análise de tendência da série temporal dos chamados

Para cada curva usada no ajuste, há um resíduo, que é a diferença entre o valor estimado para a série pela curva e o valor efetivamente observado na série. A Tabela 3, mostra as variâncias dos resíduos para a série estudada, sendo a curva que melhor se ajusta a ela a de menor variância. 
Tabela 3. Avaliação do ajuste da série à curva de tendência

\begin{tabular}{|c|c|c|}
\hline \multicolumn{2}{|l|}{ Tendência } & Variância residual \\
\hline \multicolumn{2}{|l|}{ Linear $(y=1107,1-25,8 t)$} & $60.221,17$ \\
\hline \multicolumn{2}{|l|}{ Quadrática $\left(y=1366,11-66,73 t+1,11 t^{2}\right)$} & $48.864,88$ \\
\hline \multicolumn{2}{|l|}{ Exponencial $\left(\mathbf{y}=\mathbf{1 0 8 4 , 2 7} \times \mathbf{0 , 9 6 3}^{\mathrm{t}}\right)$} & $56.370,96$ \\
\hline \multicolumn{2}{|l|}{ Média móvel (MM) centrada de 12 meses } & $49.809,59$ \\
\hline \multirow{4}{*}{$\begin{array}{l}\text { Média móvel exponencialmente ponderada } \\
\text { (MMEP) }\end{array}$} & $\mathrm{w}=\mathbf{0 , 1 0}$ & $52.200,64$ \\
\hline & $\mathrm{w}=\mathbf{0 , 2 5}$ & $29.959,93$ \\
\hline & $\mathrm{w}=\mathbf{0 , 5 0}$ & $11.529,95$ \\
\hline & $w=0,75$ & $2.882,49$ \\
\hline
\end{tabular}

Observando as variâncias residuais de cada curva e os gráficos anteriores, podem ser feitas as seguintes considerações sobre o ajuste da curva de tendência:

(1)Embora para os fins deste trabalho a falta de valores de tendência no fim e no início da série não seja estritamente prejudicial, o uso da média móvel centrada de 12 meses foi descartado;

(2)Comparando as tendências quadrática e exponencial, apesar desta possuir uma variância residual menor que aquela, a última parece captar de maneira mais adequada certa tendência de queda dos valores da série ao longo do tempo;

(3)A MMEP, quando calculada com pesos maiores ajusta bem a série, mas prejudica a visão da tendência.

\subsubsection{Cálculo dos Î́ndices de Sazonalidade}

O gráfico da Figura 9 mostra os índices de sazonalidade calculados, com uma linha correspondendo a cada um dos métodos.

Apesar das variações características de cada método, vê-se que os três conseguem capturar em linhas gerais os movimentos de altas e baixas no número de chamados.

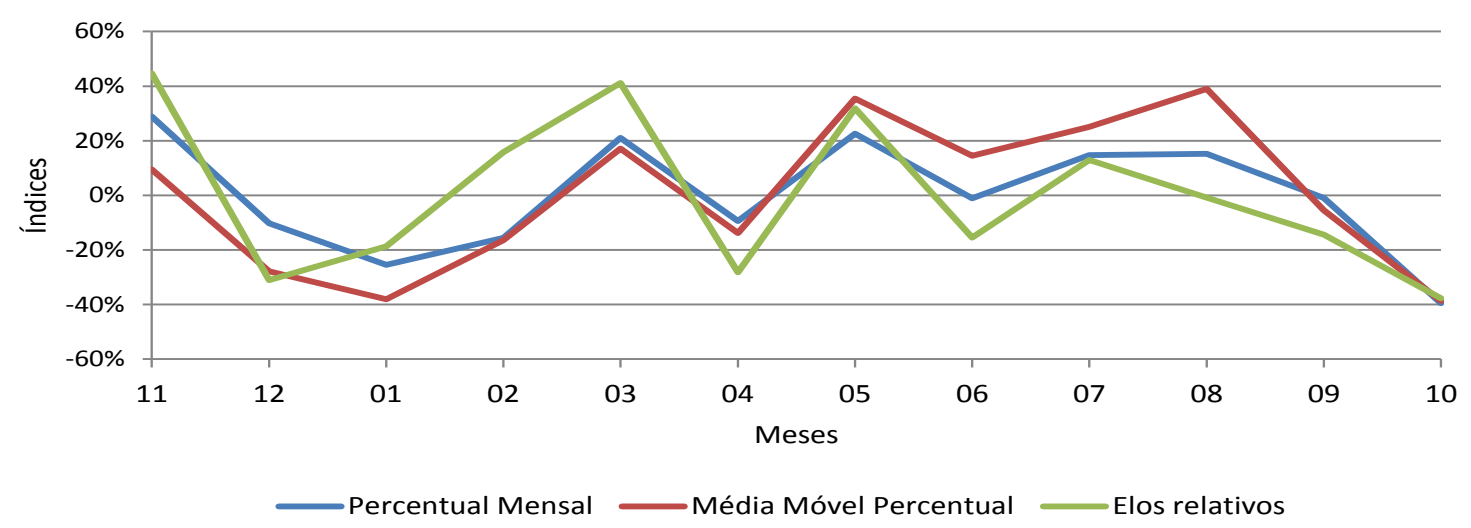

Figura 9. Índices de sazonalidade

Neste trabalho foi feita a opção pelo método das percentagens médias, que não apresenta o inconveniente da ausência de valores calculados para os meses de início e fim da série (como na a média móvel) e que conduz a menores coeficientes de variação 
em relação aos valores mensais de cada período que o os outros métodos (Figura 10, sendo mostrados os índices determinados pelo modelo multiplicativo).

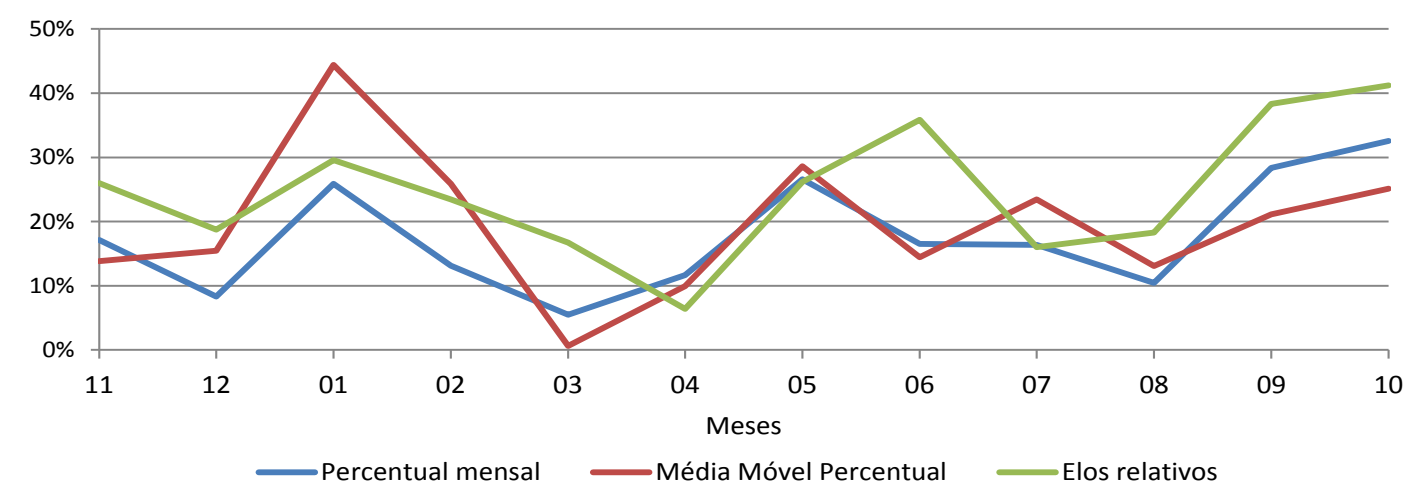

Figura 10. CVs dos índices de sazonalidade em relação às variações mensais

\subsubsection{Desestacionalização da série}

Os índices de sazonalidade determinados na seção anterior são usados para o cálculo dos valores da série desestacionalizada ${ }^{3}$. O gráfico da Figura 11 mostra a série original comparada com aquela cujos dados foram desestacionalizados.

Aqui tem-se uma primeira percepção de que, apesar do apuro da aplicação das técnicas, os resultados não deixam de ser um pouco decepcionantes para o objetivo de buscar tipicidade na distribuição de atividades ao longo do tempo. As curvas de dados desestacionalizados parecem remeter alguma tipicidade?

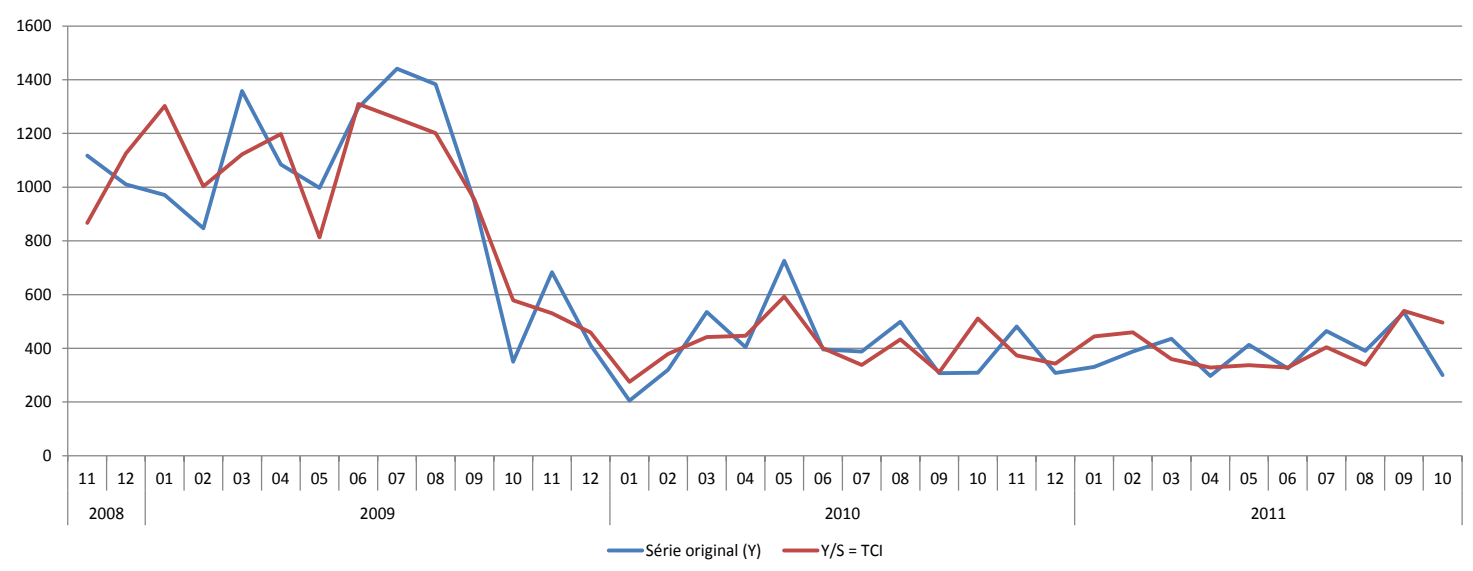

Figura 11. Dados desestacionalizados

Para este objetivo, os resultados são pouco satisfatórios. Qualquer que seja a tendência usada existem variações irregulares (conforme poderá ser visto a seguir, na Figura 12), que tornam impraticável a determinação dos valores típicos para a série. Outra observação: a curva que melhor ajusta a série diferencia-se mais das outras no seu terço inicial, ou seja, excetuando-se aquele trecho, outras curvas aparentemente ajustam a série de forma similar. Esta situação forneceu alternativa para a continuidade deste

\footnotetext{
${ }^{3}$ Mês a mês, de Novembro a Outubro, eles são: 128,8\%, 89,8\%, 74,5\%, 84,4\%, 121,0\%, 90,5\%, 122,6\%, $98,9 \%, 114,8 \%, 115,2 \%, 99,0 \%$ e $60,5 \%$.
} 
trabalho. Estariam aquelas curvas camuflando uma variação ou característica da série original que não foi explorada adequadamente? Quando foram plotados no mesmo gráfico a série original com as médias e medianas da quantidade de chamados em cada período anual ocorreu melhor compreensão do comportamento da série.

\subsubsection{Estudo das variações Cíclicas e Irregulares}

Neste estudo é usada a série de dados já desestacionalizada e com a tendência removida. Considerando as observações feitas ao fim da Seção 2.2.1, vários ensaios de remoção de tendência foram feitos. Na busca por tipicidade na distribuição de chamados, deseja-se a decomposição que resulte na menor amplitude de variações cíclicas e irregulares. $\mathrm{O}$ resultado pode ser visto na Figura 12.

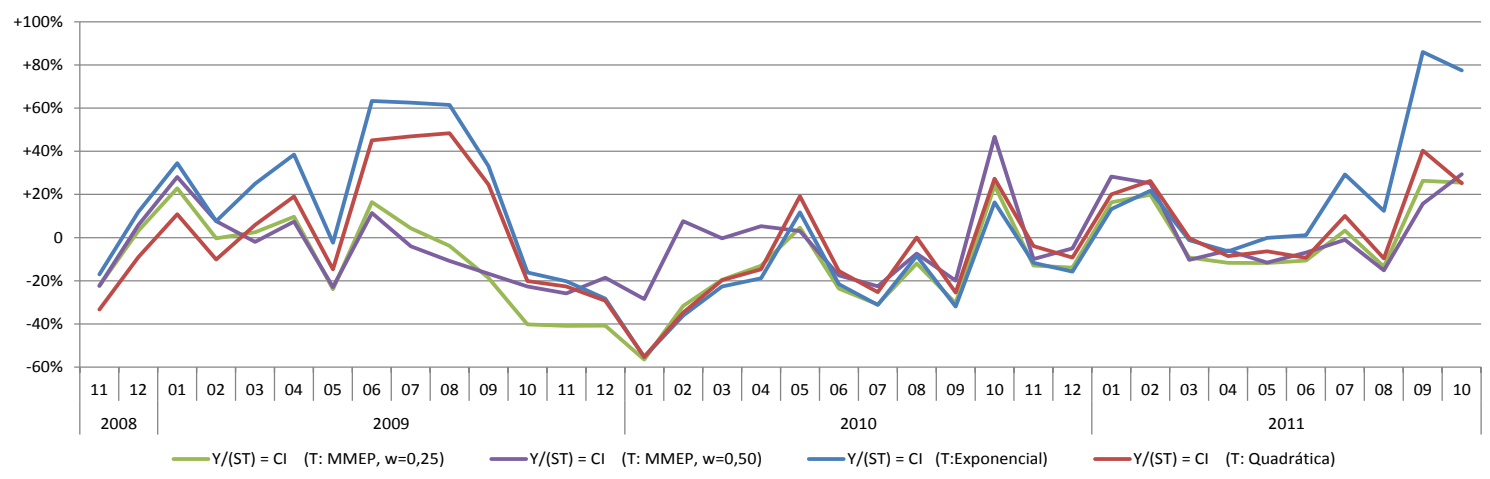

Figura 12. Variações Cíclicas e Irregulares

\subsubsection{Mudança de patamar - uma nova série se revela}

O gráfico da série original, quando plotado juntamente com as médias e medianas da quantidade de chamados de cada período anual (Figura 13), permitiu a observação mais clara de uma situação que já havia se mostrado por achados mais sutis.

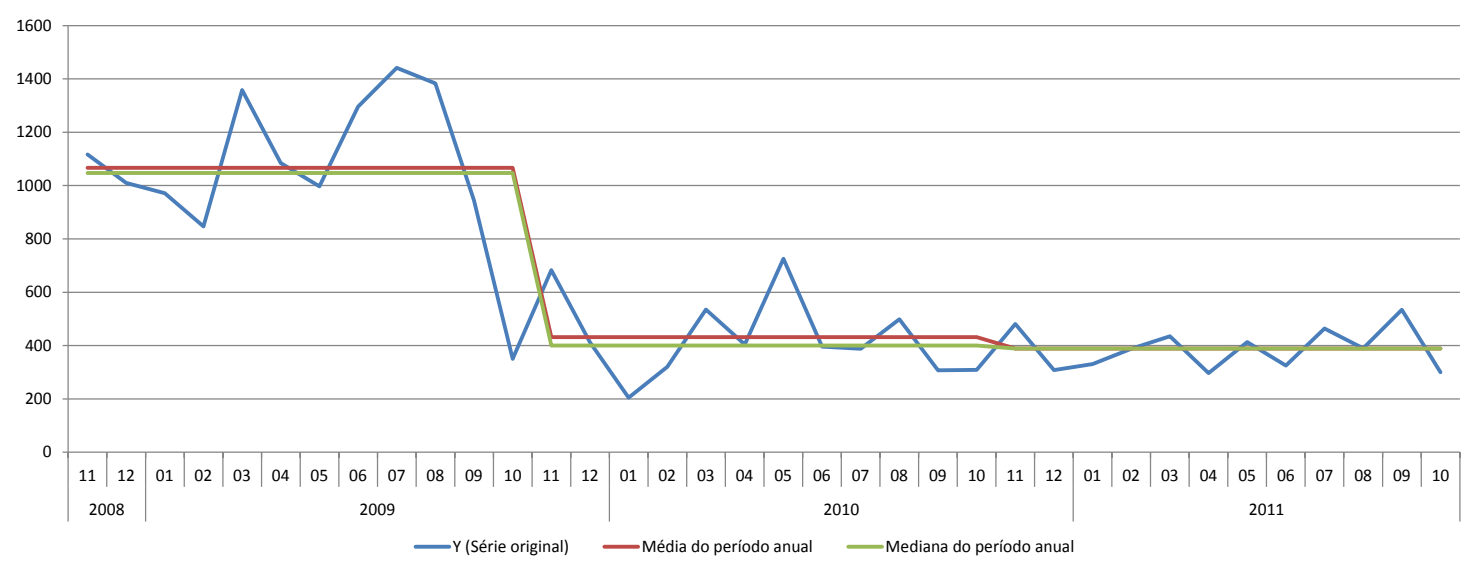

Figura 13. Patamares distintos na série temporal dos chamados

Percebe-se uma mudança de patamar bastante brusca ao final do primeiro período anual e depois o patamar permanece praticamente inalterado. $\mathrm{O}$ movimento de chamados no primeiro período anual é bastante distinto dos demais, o que justificaria a realização do ajuste apropriado para tratamento da série e busca de sua tipicidade. Talvez se pudesse questionar que este ajuste descaracterizaria a série, mas ao lembrar que a busca da tipicidade reflete o desejo de fornecer aos gestores instrumentos que 
permitissem se antecipar às demandas (adequando sua operação) e que o ajuste de maior relevância se dará na parte temporalmente mais longínqua da série, conclui-se que o benefício de fazê-lo é maior do que o suposto prejuízo. $\mathrm{Na}$ Seção 2.3 são correlacionadas as análises e descobertas com os dados e situações reais e são especuladas as razões para que tal situação tenha ocorrido. O resultado da aplicação do fator de ajuste ${ }^{4}$ aparece na Figura 14.

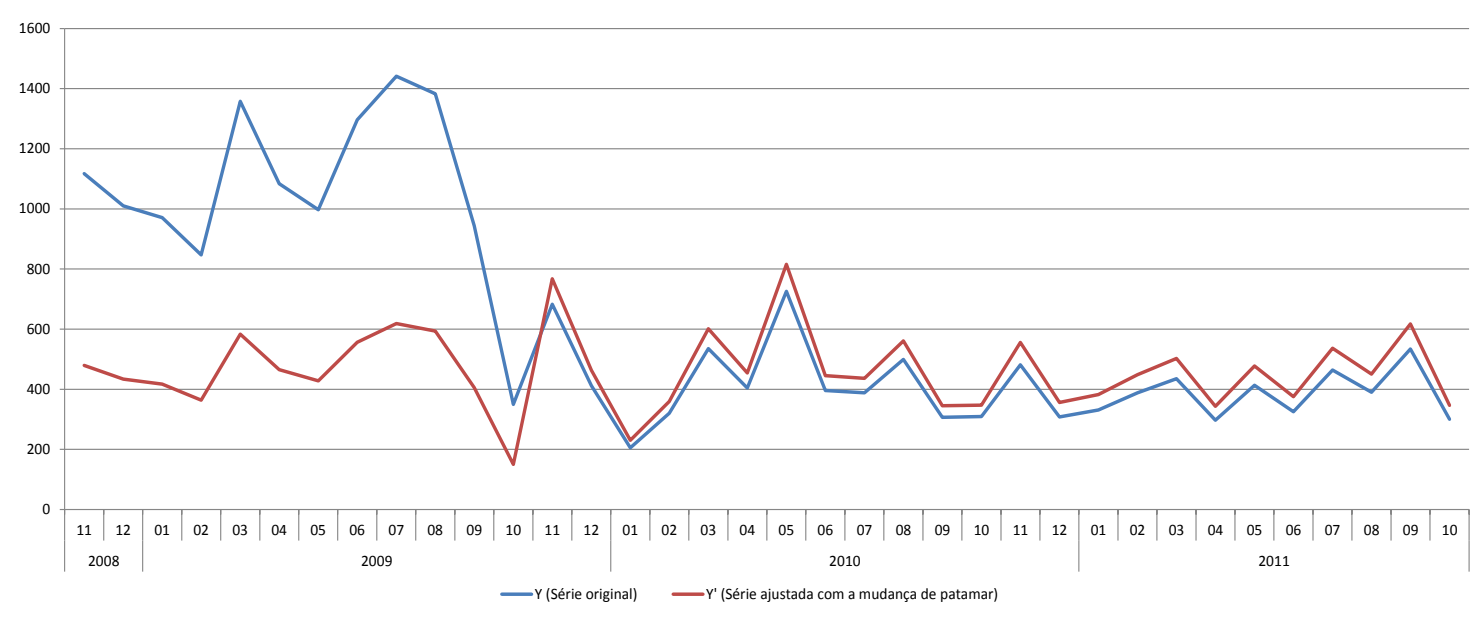

Figura 14. Série dos chamados ajustada com mudança de patamar

\subsubsection{Análise da nova série temporal}

A partir da transformação feita em 2.2.5, tem-se uma nova série $\left(Y^{\prime}\right)$, na qual tiveram de ser repetidos os estudos feitos para a série temporal original, ou seja, determinação dos índices de sazonalidade $\left(S^{\prime}\right)$, tendência $\left(T^{\prime}\right)$, variações cíclicas $\left(C^{\prime}\right)$ e irregulares $\left(I^{\prime}\right)$.

\subsubsection{Determinação da tendência da série ajustada}

Os métodos mostrados na Tabela 1 foram replicados na nova série e as equações para as linhas de tendência linear, quadrática e exponencial já evidenciam uma característica interessante da nova série.

Como se vê na Tabela 4, as equações mostram tendências de queda bastante suaves, quase mantendo a série em valores estáveis, situação que é desejável para o objetivo do trabalho, de obter valores típicos para a quantidade de chamados. Para melhor visualização, apenas as curvas de tendência aparecem na Figura 15 e na Figura 16.

Tabela 4. Avaliação do ajuste da nova série à curva de tendência

\begin{tabular}{|c|c|}
\hline Tendência & Variância residual \\
\hline Linear $\left(y^{\prime}=479,28-0,81 t\right)$ & $16.939,30$ \\
\hline Quadrática $\left(y^{\prime}=465,86+1,304 t-0,057 t^{2}\right)$ & $16.908,84$ \\
\hline Exponencial $\left(y^{\prime}=\mathbf{4 5 2 , 5 8} \times \mathbf{0 , 9 9 9 ^ { t }}\right)$ & $16.955,35$ \\
\hline Média móvel (MM) centrada de 12 meses & $21.464,76$ \\
\hline
\end{tabular}

\footnotetext{
${ }^{4}$ A determinação do fator de ajuste envolveu a busca de um índice $P$ que pudesse transformar a série $Y=$ TCSI na série $Y^{s}=\frac{Y}{P}=T^{v} C^{v} S^{v} I^{s}$. O fator de ajuste usado foi $P=\frac{\text { Mediana do periodo anual }}{\text { Mediana de toda a série }}$
} 


\begin{tabular}{|l|c|c|}
\hline \multirow{4}{*}{$\begin{array}{l}\text { Média móvel exponencialmente ponderada } \\
\text { (MMEP) }\end{array}$} & $\mathbf{w}=\mathbf{0 , 1 0}$ & $15.070,17$ \\
\cline { 2 - 3 } & $\mathbf{w}=\mathbf{0 , 2 5}$ & $11.854,35$ \\
\cline { 2 - 3 } & $\mathbf{w}=\mathbf{0 , 5 0}$ & $6.417,03$ \\
\cline { 2 - 3 } & $\mathbf{w}=\mathbf{0 , 7 5}$ & $1.604,26$ \\
\hline
\end{tabular}

\subsubsection{Determinação dos índices de sazonalidade da série ajustada}

O método das percentagens médias poderia ser replicado na nova série integralmente, mas analisando-se melhor, vê-se que na primeira parte do método, o cálculo da razão (\%) entre a quantidade do mês e a média de quantidade do período anual, é necessário achar $R^{\prime}=\frac{Y_{t}^{t}}{\left(\frac{\sum Y_{t}^{\prime}(p e r)}{12}\right)}$. Mas, lembrando que $Y_{t}^{\prime}=\frac{Y_{t}}{p}$, com $P=\frac{\text { Mediana do período anual }}{\text { Mediana de toda a série }}$, vêse que $\mathrm{P}$ varia apenas dentro de um período anual para outro, permanecendo constante dentro de um mesmo período. Portanto, $R^{\prime}=R=\frac{Y_{t}}{\left(\frac{2 Y_{t} \text { (per) }}{12}\right)}$.

Assim, os índices de sazonalidade são aqueles já calculados para a série original, ou seja, $S^{\prime}=S$.

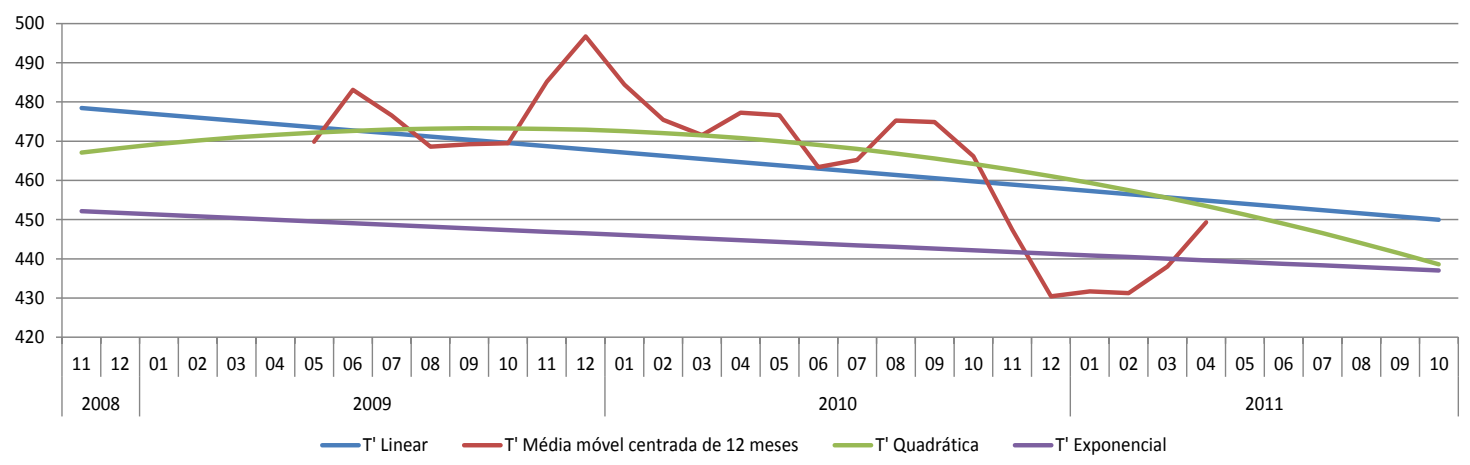

Figura 15. Curvas de tendência para a série ajustada (1)

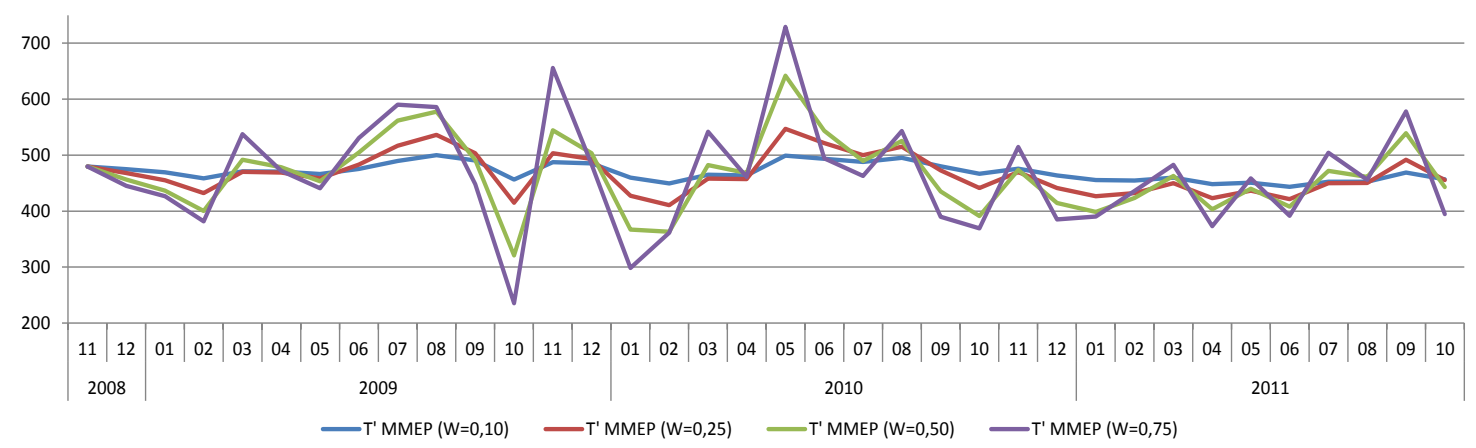

Figura 16. Curvas de tendência para a série ajustada (2)

\subsubsection{Desestacionalização da séria ajustada}

A desestacionalização da nova série seguiu o modelo já mostrado na Seção 2.2.3. A representação gráfica dos resultados aparece na Figura 17. 


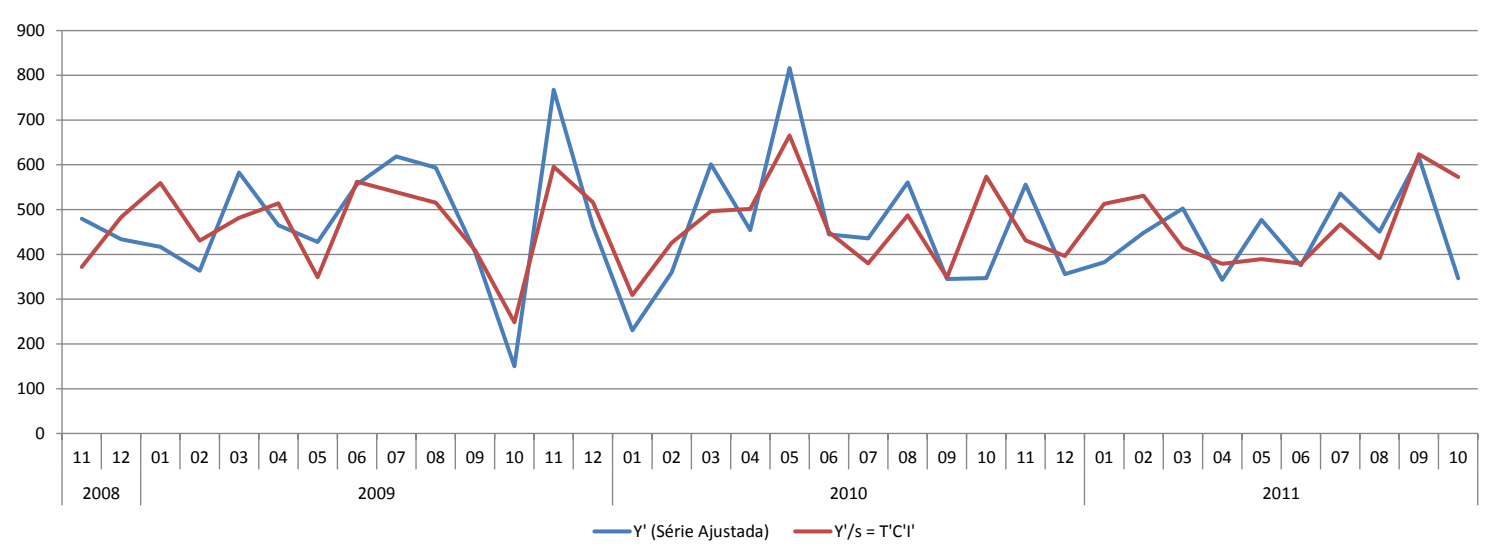

Figura 17. Dados desestacionalizados da série ajustada

\subsubsection{Variações cíclicas e irregulares da série ajustada}

Aqui foram replicados os cálculos já mostrados na Seção 2.2.4. A representação gráfica dos resultados aparece na Figura 18.

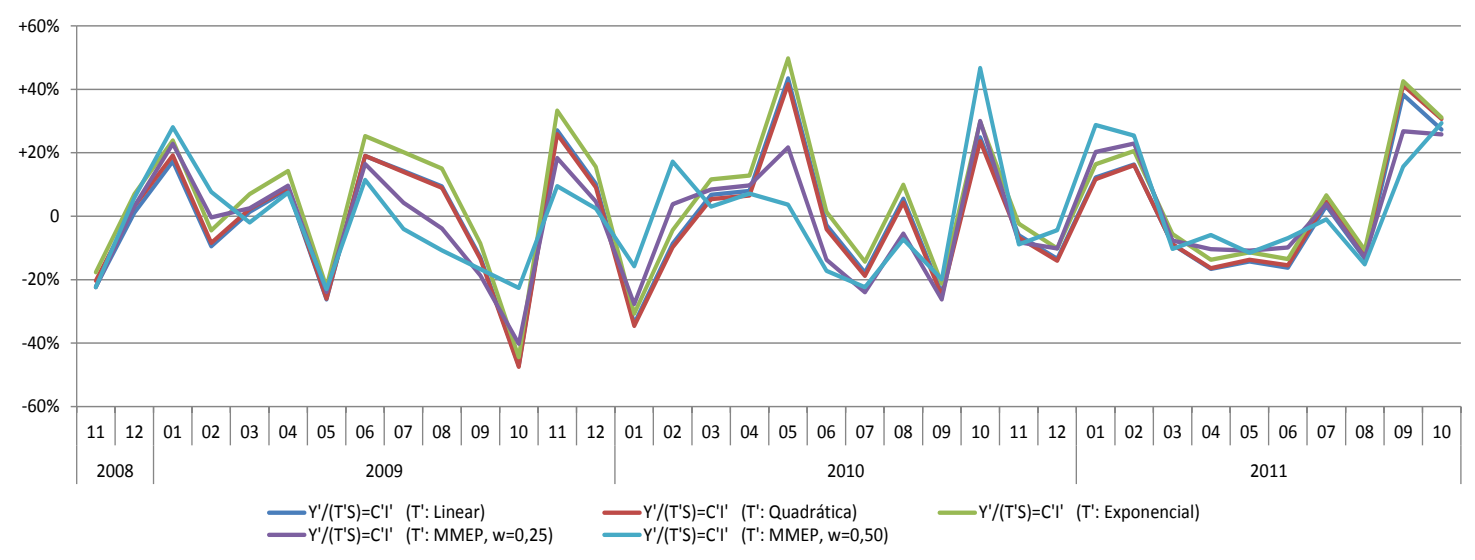

Figura 18. Variações cíclicas e irregulares da série ajustada

Neste momento o leitor é convidado a comparar o gráfico da Figura 12 com o da Figura 18. Houve significativa redução das variações irregulares, todavia elas ainda estão presentes e não são desprezíveis.

\subsection{Achados úteis e considerações para a gestão do Centro de Suporte}

(1) À parte a variação de patamares vista, a série tem comportamento quase estacionário, com ligeira tendência de queda no longo prazo. Embora preocupante do ponto de vista de negócios, esta informação é importante para balizar ações de aumento do volume de serviços;

(2) Grandes variações irregulares estão presentes, tornando previsões de curto prazo difíceis de serem feitas' Isto embasa a necessidade de que a operação do Centro de Suporte possuísse reserva de pessoal para acomodar as variações positivas e agilidade na gestão para redirecionar pessoal para outras atividades quando houvesse queda no número de chamados. Isto poderia, por exemplo, envolver estratégias de aproximação com os clientes em momentos de menor atividade;

(3) Os índices de sazonalidade são indicadores importantes para o planejamento de 
atividades anuais, como férias e treinamentos;

(4) Um eventual questionamento a respeito de a estacionariedade da série temporal estar ligado a alguma limitação na capacidade de atendimento, não se sustenta. A existência de variações irregulares positivas já seria prova em contrário. Uma limitação na capacidade de atendimento seria, em grande parte, causada por deficiência de pessoal. O tamanho da equipe técnica variou como na Figura 19.

Em dois momentos a empresa $\mathrm{X}$ realizou redução forçada do quadro (demissões) para adequar seus custos à demanda decrescente: Abr/2009 e Ago/2009. Fora isto, houve movimentos de flutuação naturais, em sua maioria por iniciativa dos seus próprios funcionários. Isto faz crer que a limitação na quantidade de chamados, esteve relacionada aos clientes ou a alguma forma de controle sobre a abertura dos chamados. De fato, percebeu-se o aumento da "filtragem" de chamados encaminhados à empresa $\mathrm{X}$, que ocorreu como forma de contenção de despesas dos clientes;

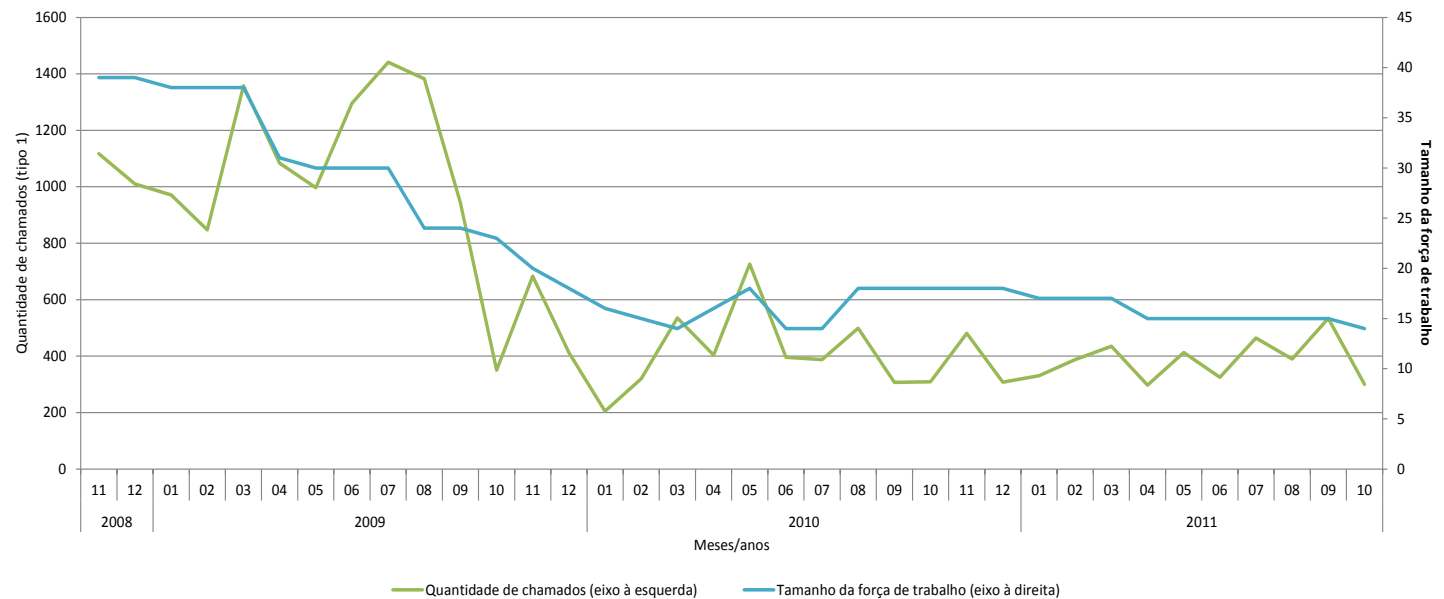

Figura 19. Volume de chamados vs. Quadro de pessoal

(5)A mudança de patamar verificada do $1^{\circ}$ período anual para os demais teve grande influência na forma como este estudo teve de ser conduzido. Haveria alguma explicação relacionada ao ambiente de negócios que justificasse este acontecimento? A especulação que se pode fazer está relacionada ao momento pelo qual passavam os clientes da empresa $X$, com uma possível redução no volume de negócios afetando as atividades tratadas através de chamados do Tipo 1. Deve-se lembrar também que o período 2008/2009 foi fortemente afetado pelo ambiente econômico global, desencadeado a partir de dificuldades nos EUA e Europa. Isto pode ter forçado as empresas a reverem seus projetos, levando-as a novos patamares de volumes de negócios.

\subsection{Distribuição de chamados ao longo de um dia típico}

Uma vez estabelecida a tipicidade da distribuição mensal de chamados, isto permitiria que os gestores do Centro de Suporte se antecipassem a demandas e ajustassem a operação para períodos de baixa ou alta atividade. O próximo passo foi avaliar a distribuição dos chamados ao longo de um dia de trabalho. Esta informação é crucial para que as escalas do pessoal de atendimento fossem estruturadas de forma mais aderente possível à curva de demanda. Idealmente, a quantidade de pessoal deveria ser 
suficiente para atender a demanda da hora de pico, então o primeiro problema é determinar quando ela ocorre num dia típico e que quantidade de chamados ela representa.

\subsubsection{Determinação da hora de pico}

Para referência, aqui se usa o conceito de faixa de horário, que é o período de tempo dentro do qual um chamado teve início; assim, um chamado iniciado às 11:17, por exemplo, pertence à faixa das 11:00 às 12:00. Para a descoberta da hora de pico, cada um dos dias da amostra teve atribuídos às suas faixas de horário uma hierarquização inversa para a ocupação, sendo a faixa mais ocupada a de ordem 1. Explicando melhor: num dia hipotético em que todas as faixas tivessem chamados registrados e que as quantidades fossem todas distintas, a faixa mais ocupada teria ordem 1, a faixa menos ocupada teria ordem 24 e as demais receberiam ordens de acordo com sua ocupação. Foram vistos dois resultados importantes:

(1) A dispersão dos ordenamentos é bastante grande (723 dias na amostra, com 717 distribuições diferentes). Achar tipicidade é um objetivo muito difícil;

(2) Há clara prevalência nos horários de maior fluxo de chamados, que acontecem às 10:00 e às 14:00 e representam quase $83 \%$ dos casos,com máximas de 65 e 72 acessos, respectivamente.

A probabilidade de ocorrência do pico horário indica para a gestão do Centro de Suporte em que momento(s) do dia ele deveria alocar a maior quantidade de seus recursos, mas ainda não permite determinar como esta alocação deveria ser feita. Ainda, como as escalas de trabalho implicam um compromisso de alocação de um profissional por 8 horas corridas, algumas escolhas teriam de ser feitas para não se gerar sobrecobertura em um determinado horário e subcobertura em outro, como se verá mais à frente.

\subsubsection{Determinação da quantidade diária de chamados por faixa de horário}

Feita a distinção sobre hora de pico e volume de chamados, seguiu-se então o estudo da distribuição de chamados por faixa horária. Como o volume de chamados das 00:00 às 08:00 era irrisório (menos que 2\% do total), aquele intervalo foi expurgado da análise. Já que os chamados do Tipo 1 ocorriam majoritariamente nas faixas de horário "pares", as "ímpares" foram acumuladas nas faixas "pares" imediatamente anteriores (as "ímpares" eram menos de $2 \%$ do total e só ocorriam em situações excepcionais, para acomodar demandas específicas). O gráfico da Figura 20 mostra, então, a distribuição de chamados por faixa de horário para toda a amostra. 


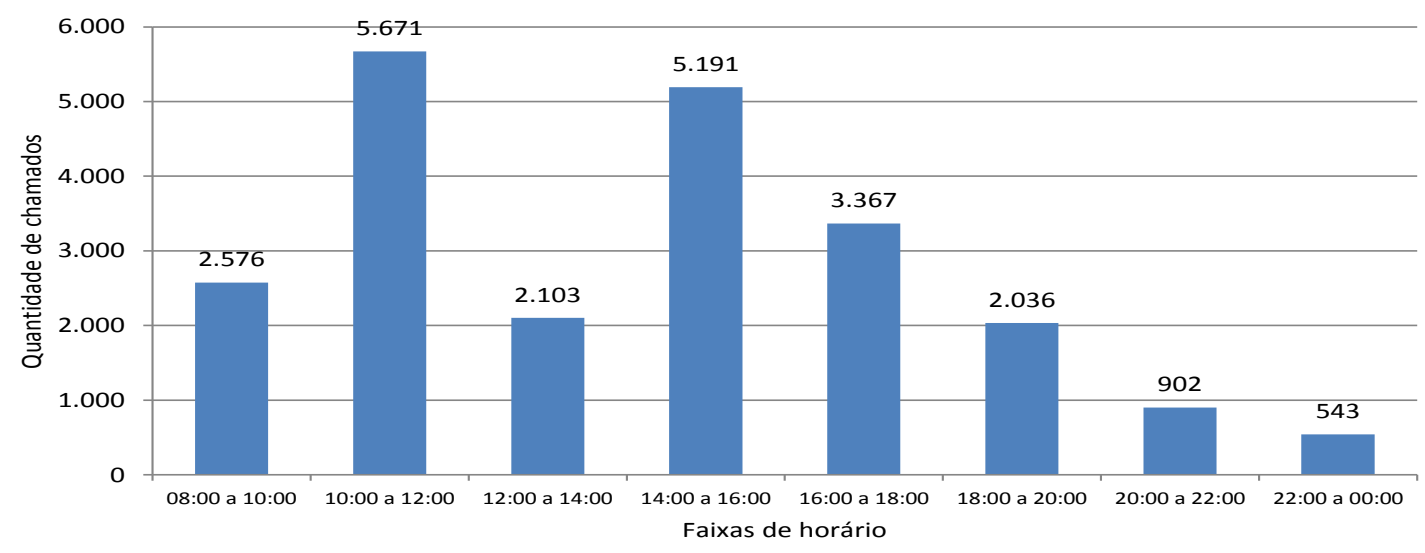

Figura 20. Distribuição dos chamados por faixa de horário

A distribuição de frequências das quantidades de chamados em cada faixa de horário mostra que há grande variação, tornando as médias (ou medianas) pouco representativas como valores típicos (Tabela 5). O mesmo ocorre quando se analisam os dados estratificados em períodos anuais. Assim, a busca por valores típicos continuou.

Tabela 5. Estatísticas da distribuição de chamados por faixas de horário

\begin{tabular}{|l|c|c|c|c|c|c|c|c|}
\hline Medida & $\begin{array}{c}08: 00 \mathrm{a} \\
10: 00\end{array}$ & $\begin{array}{c}10: 00 \mathrm{a} \\
12: 00\end{array}$ & $\begin{array}{c}12: 00 \mathrm{a} \\
14: 00\end{array}$ & $\begin{array}{c}14: 00 \mathrm{a} \\
16: 00\end{array}$ & $\begin{array}{c}16: 00 \mathrm{a} \\
18: 00\end{array}$ & $\begin{array}{c}18: 00 \mathrm{a} \\
20: 00\end{array}$ & $\begin{array}{c}20: 00 \mathrm{a} \\
22: 00\end{array}$ & $\begin{array}{c}22: 00 \mathrm{a} \\
00: 00\end{array}$ \\
\hline Média & 3,6 & 7,8 & 2,9 & 7,2 & 4,7 & 2,8 & 1,2 & 0,8 \\
\hline Mediana & 3,0 & 7,0 & 3,0 & 6,0 & 4,0 & 3,0 & 2,0 & 1,0 \\
\hline CV & $98 \%$ & $78 \%$ & $142 \%$ & $101 \%$ & $100 \%$ & $102 \%$ & $134 \%$ & $329 \%$ \\
\hline
\end{tabular}

A alternativa usada, apud (MACHADO, 2003, pp. 12-13), foi mapear os dias com quantidades de chamados similares e estudá-los à busca de semelhanças na distribuição diária de atividades. Os dias foram agrupados de duas formas:

(1) Os períodos I, II e III são, respectivamente, de Nov/08 a Out/09, de Nov/09 a Out/10 e de Out/10 em diante;

(2) Os grupos 1, 2 e 3, são aqueles que possuem até 15 chamados/dia, entre 15 e 45 chamados/dia e entre 45 e 66 chamados/dia, respectivamente. Os dias com mais de 66 chamados não foram incluídos em um grupo.

Tabela 6. Distribuição de frequências da quantidade de chamados (novo ensaio)

$\left.\begin{array}{llll}\hline \text { Classes } & \text { FR } & \text { FRAc } & \text { Percentil } \\ \hline 0-3 & 1,1 \% & 1,1 \% & 8,7 \% \\ 3-6 & 1,1 \% & 2,2 \% & 11,2 \% \\ 6-9 & 3,0 \% & 5,3 \% & 14,3 \% \\ 9-12 & 9,7 \% & 14,9 \% & 17,8 \% \\ 12-15 & 7,5 \% & 22,4 \% & 21,9 \% \\ 15-18 & 10,1 \% & 32,5 \% & 26,4 \% \\ 18-21 & 10,1 \% & 42,6 \% & 31,4 \% \\ 21-24 & 9,4 \% & 52,0 \% & 36,7 \%\end{array}\right\} \mathrm{G} 1$




\begin{tabular}{llll}
$24-27$ & $4,6 \%$ & $56,6 \%$ & $42,3 \%$ \\
$27-30$ & $5,4 \%$ & $62,0 \%$ & $48,1 \%$ \\
$30-33$ & $3,7 \%$ & $65,7 \%$ & $53,9 \%$ \\
$33-36$ & $2,5 \%$ & $68,2 \%$ & $59,7 \%$ \\
$36-39$ & $3,6 \%$ & $71,8 \%$ & $65,2 \%$ \\
$39-42$ & $2,6 \%$ & $74,4 \%$ & $70,4 \%$ \\
$42-45$ & $3,2 \%$ & $77,6 \%$ & $75,3 \%$ \\
$45-48$ & $2,6 \%$ & $80,2 \%$ & $79,6 \%$ \\
$48-51$ & $2,8 \%$ & $83,0 \%$ & $83,5 \%$ \\
$51-54$ & $4 \%$ & $87 \%$ & $86,9 \%$ \\
$54-57$ & $2 \%$ & $89 \%$ & $89,7 \%$ \\
$57-60$ & $1,9 \%$ & $90,6 \%$ & $92,1 \%$ \\
$60-63$ & $2,5 \%$ & $93,1 \%$ & $94,0 \%$ \\
$63-66$ & $1,8 \%$ & $94,9 \%$ & $95,6 \%$ \\
$>66$ & $5,1 \%$ & $100,0 \%$ & $100,0 \%$ \\
\hline
\end{tabular}

O agrupamento baseado na quantidade de chamados/dia é mais uma tentativa de buscar similaridade para a distribuição diária dos chamados. Uma tipicidade de distribuição associada, por exemplo, aos índices de sazonalidade, permitiria à gestão se antecipar aos movimentos sazonais, e tirar partido deles na alocação diária do pessoal técnico, concedendo folgas ou permitindo compensações de horas extras ou até acomodando com maior segurança picos de demanda. Então, dias foram agrupados por sua quantidade de chamados, tentando identificar aí alguma semelhança não encontrada à primeira vista. A Tabela 6 mostra o critério usado para a criação dos grupos. Aqueles com baixo volume pertencem ao G1 (frequência acumulada até próximo de $25 \%$ ), os de alto volume pertencem ao G3 (após a frequência acumulada de 75\%) e os de volume intermediário ficam no G2 (lembrando que aqueles com mais de 66 chamados/dia são os outliers da distribuição)

Tabela 7. Cálculos das médias e medianas da quantidade de chamados nos agrupamentos, por faixa de horário

\begin{tabular}{|l|l|l|l|l|l|l|l|l|l|l|l|l|}
\hline \multirow{2}{*}{$\begin{array}{l}\text { Faixas de } \\
\text { horário }\end{array}$} & \multicolumn{9}{|c|}{ Médias } & \multicolumn{7}{c|}{ Medianas } \\
\cline { 2 - 15 }$y$ & P I & P II & P III & G1 & G2 & G3 & P I & P II & P III & G1 & G2 & G3 \\
\hline 08:00 a 10:00 & 6,6 & 2,3 & 1,9 & 2,6 & 3,2 & 5,8 & 6,0 & 2,0 & 1,0 & 2,0 & 2,0 & 5,0 \\
\hline 10:00 a 12:00 & 13,2 & 5,6 & 4,9 & 5,3 & 7,2 & 12,0 & 12,0 & 5,0 & 4,0 & 4,0 & 6,0 & 12,0 \\
\hline 12:00 a 14:00 & 4,6 & 2,4 & 1,9 & 2,1 & 2,8 & 3,8 & 4,0 & 2,0 & 2,0 & 2,0 & 2,0 & 4,0 \\
\hline 14:00 a $16: 00$ & 13,0 & 4,7 & 4,1 & 5,4 & 6,6 & 11,0 & 11,0 & 4,0 & 3,0 & 4,0 & 4,0 & 11,0 \\
\hline $16: 00$ a $18: 00$ & 8,0 & 3,2 & 2,9 & 3,1 & 4,2 & 7,4 & 7,0 & 2,0 & 2,0 & 2,5 & 3,0 & 6,0 \\
\hline 18:00 a 20:00 & 4,5 & 2,2 & 1,8 & 2,1 & 2,6 & 4,0 & 4,0 & 2,0 & 1,0 & 2,0 & 2,0 & 3,0 \\
\hline 20:00 a 22:00 & 2,1 & 0,9 & 0,7 & 0,9 & 1,1 & 2,1 & 2,0 & 1,0 & 0,0 & 1,0 & 1,0 & 2,0 \\
\hline 22:00 a 24:00 & 1,2 & 0,5 & 0,6 & 0,7 & 0,6 & 1,2 & 0,0 & 0,0 & 0,0 & 0,0 & 0,0 & 0,0 \\
\hline
\end{tabular}


Foram calculadas para os agrupamentos definidos as medidas que aparecem na $\mathrm{O}$ agrupamento baseado na quantidade de chamados/dia é mais uma tentativa de buscar similaridade para a distribuição diária dos chamados. Uma tipicidade de distribuição associada, por exemplo, aos índices de sazonalidade, permitiria à gestão se antecipar aos movimentos sazonais, e tirar partido deles na alocação diária do pessoal técnico, concedendo folgas ou permitindo compensações de horas extras ou até acomodando com maior segurança picos de demanda. Então, dias foram agrupados por sua quantidade de chamados, tentando identificar aí alguma semelhança não encontrada à primeira vista. A Tabela 6 mostra o critério usado para a criação dos grupos. Aqueles com baixo volume pertencem ao G1 (frequência acumulada até próximo de $25 \%$ ), os de alto volume pertencem ao G3 (após a frequência acumulada de $75 \%$ ) e os de volume intermediário ficam no G2 (lembrando que aqueles com mais de 66 chamados/dia são os outliers da distribuição)

Tabela 7. A partir daí, relacionaram-se, pelo coeficiente de correlação, os valores médios em cada faixa de horário no agrupamento com os valores observados em cada dia. As correlações foram separadas em intervalos, segundo os graus A (alto, correlação $\geq 75 \%$ ), M (moderado, correlação entre 50 e 75\%) ou B (baixo, correlação $<50 \%$ ). Procedimento análogo foi feito com as medianas. Em todos os ensaios foram incluídos os dias da semana na análise, de forma a buscar algum eventual padrão associado a eles.

Os resultados dos ensaios aparecem na Tabela 8 e na Tabela 9 e mostram que padrões de distribuição não são facilmente detectáveis na amostra trabalhada. Não há prevalência clara de um dia da semana sobre outro e não se veem resultados muito mais favoráveis de um modelo em relação a outro.

Tabela 8. Quantidade de dias, separados pelos graus de correlação com as médias de cada agrupamento

\begin{tabular}{|c|c|c|c|c|c|c|c|c|c|c|c|c|c|c|c|c|c|c|}
\hline \multirow{2}{*}{ Dia } & \multicolumn{3}{|c|}{ P I } & \multicolumn{3}{|c|}{ P II } & \multicolumn{3}{|c|}{ P III } & \multicolumn{3}{|c|}{ G1 } & \multicolumn{3}{|c|}{ G2 } & \multicolumn{3}{|c|}{ G3 } \\
\hline & $\mathbf{A}$ & $\mathbf{M}$ & B & $\mathbf{A}$ & $\mathbf{M}$ & B & $\mathbf{A}$ & $\mathbf{M}$ & B & $\mathbf{A}$ & M & B & $\mathbf{A}$ & $\mathbf{M}$ & B & A & M & B \\
\hline SEG & 31 & 8 & 8 & 23 & 12 & 11 & 17 & 19 & 14 & 15 & 12 & 8 & 30 & 29 & 22 & 14 & 3 & 3 \\
\hline TER & 30 & 14 & 5 & 18 & 19 & 10 & 19 & 23 & 10 & 10 & 11 & 9 & 31 & 38 & 15 & 18 & 7 & 1 \\
\hline QUA & 31 & 14 & 2 & 17 & 18 & 13 & 15 & 20 & 15 & 13 & 7 & 13 & 28 & 33 & 18 & 18 & 6 & 1 \\
\hline QUI & 32 & 11 & 4 & 19 & 17 & 12 & 15 & 19 & 17 & 15 & 13 & 11 & 31 & 26 & 19 & 15 & 1 & 3 \\
\hline SEX & 34 & 12 & & 20 & 15 & 10 & 23 & 11 & 16 & 8 & 1 & 10 & 42 & 21 & 16 & 24 & 5 & \\
\hline Total & 158 & 59 & 19 & 97 & 81 & 56 & 89 & 92 & 72 & 61 & 50 & 51 & 162 & 147 & 90 & 89 & 28 & 8 \\
\hline
\end{tabular}

Tabela 9. Quantidade de dias, separados pelos graus de correlação com as medianas de cada agrupamento

\begin{tabular}{|c|c|c|c|c|c|c|c|c|c|c|c|c|c|c|c|c|c|c|}
\hline \multirow{2}{*}{ Dia } & \multicolumn{3}{|c|}{ P I } & \multicolumn{3}{|c|}{ P II } & \multicolumn{3}{|c|}{ P III } & \multicolumn{3}{|c|}{ G1 } & \multicolumn{3}{|c|}{ G2 } & \multicolumn{3}{|c|}{ G3 } \\
\hline & $\mathbf{A}$ & $\mathbf{M}$ & B & A & $\mathbf{M}$ & B & $\mathbf{A}$ & M & B & A & M & B & $\mathbf{A}$ & M & B & $\mathbf{A}$ & $\mathbf{M}$ & B \\
\hline SEG & 30 & 9 & 8 & 23 & 12 & 11 & 19 & 17 & 14 & 17 & 10 & 8 & 38 & 21 & 22 & 14 & 3 & 3 \\
\hline TER & 30 & 16 & 3 & 17 & 20 & 10 & 20 & 19 & 13 & 9 & 12 & 9 & 27 & 38 & 19 & 19 & 6 & 1 \\
\hline QUA & 32 & 13 & 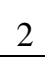 & 16 & 19 & 13 & 15 & 16 & 19 & 12 & 10 & 11 & 33 & 26 & 20 & 14 & 10 & 1 \\
\hline QUI & 34 & 10 & 3 & 15 & 22 & 11 & 13 & 19 & 19 & 16 & 14 & 9 & 36 & 16 & 24 & 14 & 8 & 3 \\
\hline
\end{tabular}




\begin{tabular}{|l|c|c|c|c|c|c|c|c|c|c|c|c|c|c|c|c|c|c|}
\hline SEX & 36 & 10 & & 21 & 13 & 11 & 19 & 17 & 14 & 6 & 9 & 10 & 40 & 24 & 15 & 22 & 7 & \\
\hline Total & $\mathbf{1 6 2}$ & $\mathbf{5 8}$ & $\mathbf{1 6}$ & $\mathbf{9 2}$ & $\mathbf{8 6}$ & $\mathbf{5 6}$ & $\mathbf{8 6}$ & $\mathbf{8 8}$ & $\mathbf{7 9}$ & $\mathbf{6 0}$ & $\mathbf{5 5}$ & $\mathbf{4 7}$ & $\mathbf{1 7 4}$ & $\mathbf{1 2 5}$ & $\mathbf{1 0 0}$ & $\mathbf{8 3}$ & $\mathbf{3 4}$ & $\mathbf{8}$ \\
\hline
\end{tabular}

Seria esperado que se o índice de sazonalidade para um dado mês fosse positivo houvesse a ocorrência de chamados no G2 maior que no G1, ou G3 maior que G2 ou ainda G3 maior que G1; Caso a sazonalidade fosse negativa, deveria ocorrer o inverso. Esta hipótese também não se sustenta por evidência estatística, exceto com alguma liberalidade no período final da amostra, conforme se vê na Tabela 10,onde na coluna "Val" o símbolo $\checkmark$ indica uma situação onde a esta hipótese é validada e $x$ onde não é.

Tabela 10. Número de dias em cada agrupamento - Comparação com os índices de sazonalidade

\begin{tabular}{|c|c|c|c|c|c|c|c|c|c|c|c|c|c|}
\hline \multirow{2}{*}{ Mês } & \multirow{3}{*}{ I.S. } & \multicolumn{4}{|c|}{ Perído I } & \multicolumn{4}{|c|}{ Período II } & \multicolumn{3}{|c|}{ Período III } \\
\hline & & G1 & G2 & G3 & Val & G1 & G2 & G3 & Val & G1 & G2 & G3 & Val \\
\hline nov & $+28,8 \%$ & & 2 & 17 & $\checkmark$ & & 16 & 3 & $\times$ & 3 & 15 & 1 & $\checkmark$ \\
\hline dez & $-10,2 \%$ & & 7 & 10 & $\times$ & 5 & 15 & & $\times$ & 11 & 10 & & $\checkmark$ \\
\hline jan & $-25,5 \%$ & & 8 & 12 & $\times$ & 7 & 6 & & $\checkmark$ & 11 & 9 & & $\checkmark$ \\
\hline fev & $-15,6 \%$ & & 6 & 10 & $\times$ & 6 & 11 & & $\times$ & 4 & 16 & & $\times$ \\
\hline mar & $+21,0 \%$ & & 5 & 8 & $\checkmark$ & 1 & 22 & & $\checkmark$ & 5 & 15 & & $\checkmark$ \\
\hline abr & $-9,5 \%$ & & 5 & 12 & $\times$ & 3 & 16 & & $\times$ & 11 & 8 & & $\checkmark$ \\
\hline mai & $+22,6 \%$ & 1 & 10 & 6 & $\times$ & 1 & 19 & 1 & $\checkmark$ & 10 & 12 & & $\checkmark$ \\
\hline jun & $-1,1 \%$ & & 1 & 17 & $\times$ & 4 & 17 & & $\times$ & 14 & 7 & & $\checkmark$ \\
\hline jul & $+14,8 \%$ & & 8 & 9 & $\checkmark$ & 9 & 11 & 1 & $\checkmark$ & 3 & 18 & & $\checkmark$ \\
\hline ago & $+15,2 \%$ & & 5 & 10 & $\checkmark$ & 4 & 17 & 1 & $\checkmark$ & 11 & 12 & & $\checkmark$ \\
\hline set & $-1,0 \%$ & 2 & 11 & 5 & $\times$ & 16 & 3 & 1 & $\checkmark$ & 1 & 20 & & $\times$ \\
\hline out & $-39,5 \%$ & & 11 & 1 & $\times$ & 8 & 10 & & $\times$ & 10 & 9 & & $\checkmark$ \\
\hline
\end{tabular}

\subsection{Novas considerações para a gestão do Centro de Suporte}

Todos os resultados oferecem à gestão insumos para ponderar sua decisão com base em evidências estatísticas. Ela poderia concluir, por exemplo, que os agrupamentos G1 e G2 descrevem razoavelmente o comportamento da demanda diária, especialmente no período final da amostra, e que isto serviria para um melhor ajustamento de escalas para os períodos à frente (pois já foi concluído aqui também que a série temporal é praticamente estável). Neste cenário, ela poderia optar por montar suas escalas de trabalho usando os números da $\mathrm{O}$ agrupamento baseado na quantidade de chamados/dia é mais uma tentativa de buscar similaridade para a distribuição diária dos chamados. Uma tipicidade de distribuição associada, por exemplo, aos índices de sazonalidade, permitiria à gestão se antecipar aos movimentos sazonais, e tirar partido deles na alocação diária do pessoal técnico, concedendo folgas ou permitindo compensações de horas extras ou até acomodando com maior segurança picos de demanda. Então, dias foram agrupados por sua quantidade de chamados, tentando identificar aí alguma 
semelhança não encontrada à primeira vista. A Tabela 6 mostra o critério usado para a criação dos grupos. Aqueles com baixo volume pertencem ao G1 (frequência acumulada até próximo de $25 \%$ ), os de alto volume pertencem ao G3 (após a frequência acumulada de $75 \%$ ) e os de volume intermediário ficam no G2 (lembrando que aqueles com mais de 66 chamados/dia são os outliers da distribuição)

Tabela 7 e, sendo conservador, poderia considerar a demanda como igual ao menor valor inteiro maior que os valores encontrados (teto):

Tabela 11. Determinação da demanda com base nos dados já obtidos

\begin{tabular}{|c|c|c|c|c|c|c|c|c|}
\hline $\begin{array}{c}\text { Estatísticas } \\
\text { usadas }\end{array}$ & $\begin{array}{c}08: 00 \\
\mathbf{a} \\
10: 00\end{array}$ & $\begin{array}{c}10: 00 \\
a \\
12: 00\end{array}$ & $\begin{array}{c}12: 00 \\
a \\
14: 00\end{array}$ & $\begin{array}{c}14: 00 \\
a \\
16: 00\end{array}$ & $\begin{array}{c}16: 00 \\
a \\
18: 00\end{array}$ & $\begin{array}{c}18: 00 \\
a \\
20: 00 \\
\end{array}$ & $\begin{array}{c}20: 00 \\
a \\
22: 00\end{array}$ & $\begin{array}{c}22: 00 \\
a \\
00: 00\end{array}$ \\
\hline Média G1 & 2,6 & 5,3 & 2,1 & 5,4 & 3,1 & 2,1 & 0,9 & 0,7 \\
\hline Média G2 & 3,2 & 7,2 & 2,8 & 6,6 & 4,2 & 2,6 & 1,1 & 0,6 \\
\hline Mediana G1 & 2 & 4 & 2 & 4 & 2,5 & 2 & 1 & 0 \\
\hline Mediana G2 & 2 & 6 & 2 & 4 & 3 & 2 & 1 & 0 \\
\hline $\begin{array}{c}\text { Demanda } \\
\text { (Teto) }\end{array}$ & 4 & 8 & 3 & 7 & 5 & 3 & 2 & $\mathbf{1}$ \\
\hline
\end{tabular}

É claro que outros cenários poderiam ser considerados, de acordo com as convicções, dados de negócio ou percepções intangíveis dos gestores. Como ilustração, a Tabela 12 mostra, percentualmente, em quantos dias a demanda real é menor ou igual à demanda prevista, ou seja, quanto o cenário escolhido serve para representar a demanda para os propósitos da gestão do Centro de Suporte.

Tabela 12. Cenário de estudo

\begin{tabular}{|c|c|c|c|c|c|c|c|c|}
\hline $\begin{array}{c}\text { Período da } \\
\text { amostra }\end{array}$ & $\begin{array}{c}\mathbf{0 8 : 0 0 a} \\
\mathbf{1 0 : 0 0}\end{array}$ & $\begin{array}{c}\mathbf{1 0 : 0 0} \\
\mathbf{a}\end{array}$ & $\begin{array}{c}\mathbf{1 2 : 0 0} \\
\mathbf{a}\end{array}$ & $\begin{array}{c}\mathbf{1 4 : 0 0} \\
\mathbf{a}\end{array}$ & $\begin{array}{c}\mathbf{1 6 : 0 0} \\
\mathbf{a}\end{array}$ & $\begin{array}{c}\mathbf{1 8 : 0 0} \\
\mathbf{a}\end{array}$ & $\begin{array}{c}\mathbf{2 0 : 0 0} \\
\mathbf{a}\end{array}$ & $\begin{array}{c}\mathbf{2 2 : 0 0} \\
\mathbf{a} \\
\mathbf{1 6 : 0 0}\end{array}$ \\
\hline Período I & $33,1 \%$ & $17,8 \%$ & $44,1 \%$ & $18,6 \%$ & $34,7 \%$ & $49,2 \%$ & $65,3 \%$ & $80,5 \%$ \\
\hline Período II & $85,9 \%$ & $84,2 \%$ & $81,2 \%$ & $81,6 \%$ & $82,9 \%$ & $79,5 \%$ & $91,5 \%$ & $86,8 \%$ \\
\hline Período III & $92,9 \%$ & $86,2 \%$ & $90,9 \%$ & $88,5 \%$ & $85,4 \%$ & $90,1 \%$ & $96,0 \%$ & $88,1 \%$ \\
\hline Geral & $\mathbf{7 1 , 1 \%}$ & $\mathbf{6 3 , 2 \%}$ & $\mathbf{7 2 , 5 \%}$ & $\mathbf{6 3 , 5 \%}$ & $\mathbf{6 8 , 0 \%}$ & $\mathbf{7 3 , 3 \%}$ & $\mathbf{8 4 , 5 \%}$ & $\mathbf{8 5 , 2 \%}$ \\
\hline
\end{tabular}




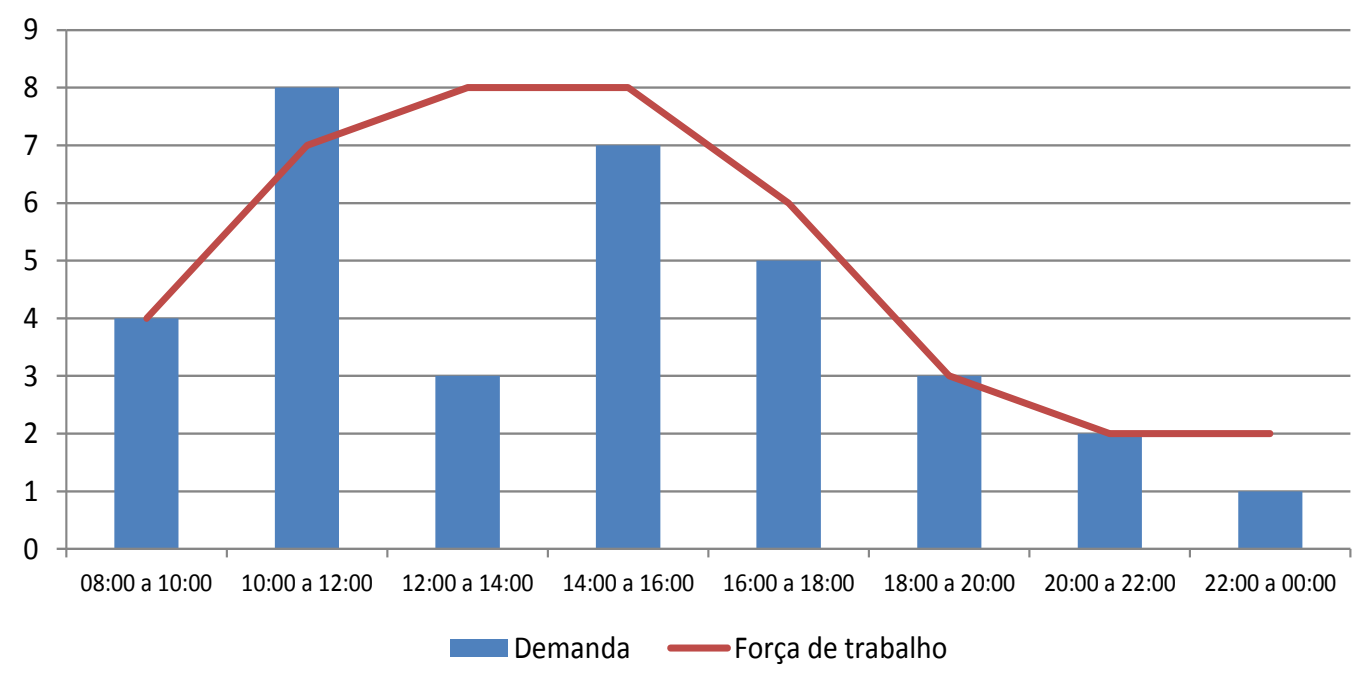

Figura 21. Demanda prevista vs força de trabalho

E agora que já se tem determinado o comportamento da demanda, pode-se alocaro pessoal para cobertura da mesma. Por exemplo, usando quatro escalas, com 4 técnicos trabalhando das 08:00 às 16:00, 3 técnicos das 10:00 às 18:00, 1 técnico das 12:00 às 20:00 e 2 técnicos das 16:00 às 00:00, vê-se o resultado da Figura 21

A escolha das escalas foi feita na tentativa de cobrir a demanda projetada, mas podem ser vistos horários de sobrecobertura (por exemplo, das 12:00 às 18:00) e subcobertura (das 10:00 às 12:00). $\mathrm{O}$ ajuste fino das escalas precisa ser feito tomando não só a demanda como base, mas também outras variáveis intangíveis e a experiência dos gestores.

Por último, mas não menos importante é considerar a satisfação dos clientes do Centro de Suporte como indicador do acerto dos ajustes feitos na cobertura da demanda, conforme se pode depreender do trabalho de (OLIVEIRA \& JOIA, 2009).

\section{Conclusões e considerações finais}

Este trabalho foi capaz de gerar informações bastante úteis para a gestão do Centro de Suporte da empresa X. Não só ficaram evidentes os movimentos sazonais como também mais claras as tendências de volumes de serviço e variações de curto prazo que precisavam ser acomodadas. É marcante a característica de irregularidade na ocorrência de chamados. Isto mostra que o dia-a-dia do Centro de Suporte precisava ser administrado com maior proximidade com os clientes, pela busca por recursos para atendimento aos picos de demandas. No longo prazo, verificaram-se evidências de certa estagnação no volume de serviços, em princípio não causada por falhas nos serviços prestados. Embora o presente estudo tenha sido realizado sobre dados do passado, os métodos aqui usados, com pequenos ajustes, têm plena possibilidade de aplicação em situações correntes.

\subsection{Sugestões de trabalhos complementares}

- Estabelecidos os métodos de tratamento e análise das quantidades e distribuições de chamados do Tipo 1, o mesmo deveria ser feito para os chamados do Tipo 2. Isto, contudo, deixará de ser feito aqui, ficando como sugestão para um novo trabalho; 
- Outro trabalho poderia determinar se há uma distribuição diária de chamados que melhor represente a amostra (ou mesmo se há uma distribuição que possa ser definida como a melhor). Neste sentido, recomenda-se a leitura de (AVRAMIDIS, et al., 2004) e (ALDOR-NOIMAN, et al., 2009);

- Com base nas análises realizadas, seria possível realizar uma predição do movimento dos chamados de Tipo 1 para os meses subsequentes, como em (TAKEDA, 2012), (ALMEIDA, 2008) ou (BOUZADA, 2006). Um trabalho mais avançado poderia envolver a geração de um método de predição que pudesse fornecer a previsão ajustada para os meses subsequentes;

- A escala de trabalho para adequação à demanda prevista com exemplos de sobrecobertura e subcobertura merece um estudo sobre a possibilidade de se estabelecer uma escala que maximize a produtividade esperada, à semelhança do mostrado em (MENDES, et al., 2006).

\section{Referências}

ALDOR-NOIMAN, S., FEIGIN, P. D. \& MANDELBAUM, A., 2009. Workload forecasting for a call center: methodology and a case study. The Annals of Applied Statistics, pp. 1403-1447.

ALMEIDA, P. M. d., 2008. Avaliação de ferramentas para análise de séries temporais e métodos de previsão. Resende: Universidade do Estado do Rio de Janeiro.

ALVES, D. D. et al., 2009. Modelagem da previsão de ligações em um call center. São Carlos, Anais da $54^{\mathrm{a}}$ RBRAS e 13 SEAGRO.

AVRAMIDIS, A. N., DESLAURIERS, A. \& L'ECUYER, P., 2004. Modeling daily arrivals to a telephone call center. Management Science, pp. 896-908.

BARBOSA, C. d. S., 2010. Uma Aplicação do Shift Design Problem à Criação, Via Metaheurísticas, dos Horários de Trabalho dos Funcionários de Call Centers com Intervalos de Pausas e Dias de Descanso. Belo Horizonte: Centro Federal de Educação Tecnológica de Minas Gerais.

BOUZADA, M. A. C., 2006. O uso de ferramentas quantitativas em call centers - $o$ caso Contax. Rio de Janeiro: COPPEAD/UFRJ.

BOUZADA, M. A. C., 2012. Aprendendo Decomposição Clássica: Tutorial para um Método de Análise de Séries Temporais. TAC - Tecnologias de Administração e Contabilidade, pp. 1-18.

FUKUNAGA, A. et al., 2002. Staff Scheduling for Inbound Call Centers and Customer Contact Centers. Sunnyvale: American Association for Artificial Intelligence (www.aaai.org).

GÄRTNER, J., MUSLIU, N. \& SLANY, W., 2001. Rota - a research project on algorithms for workforce scheduling and shift design optimization. Artificial Intelligence Communications, pp. 83-92.

MACHADO, M. T., 2003. Estabelecimento de planos horários baseados no padrão do fluxo de tráfego em função dos índices de sazonalidade. Rio de Janeiro: Universidade do Estado do Rio de Janeiro. 
MENDES, F., LUCET, C. \& MOUKRIM, A., 2006. Tabu Search to Plan Schedules in a Multiskill Customer Contact Center. Troyes, Institute of Electrical and Electronics Engineers (www.ieee.org), pp. 1126 - 1131.

MILESKI JUNIOR, A., 2007. Análise de métodos de previsão de demanda baseados em séries temporais em uma empresa do setor de perfumes e cosméticos. Curitiba: Universidade Católica do Paraná.

MUSLIU, N., SCHAERF, A. \& SLANY, W., 2004. Local search for shift design. European Journal of Operational Research , p. 51-64.

OLIVEIRA, A. F. \& JOIA, L. A., 2009. Indicadores operacionais de call centers e satisfação dos clientes: uma investigação explano-exploratória. Revista Eletrônica de Sistemas de Informação.

PELLEGRINI, F. R. \& FOGLIATTO, F. S., 2001. Passos para implantação de sistemas de previsão de demanda - técnicas e estudo de caso. Revista Produção, pp. 43-64.

REIS, M. M., 2013. INE 7001 - Estatística para Administradores I. [Online] Available at: http://www.inf.ufsc.br/ marcelo/INE7001.html

ROBBINS, T. R. \& HARRISON, T. P., 2010. A stochastic programming model for scheduling call centers with global Service Level Agreements. European Journal of Operational Research, p. 1608-1619.

SICA, P. d. \& RIBEIRO, J. L. D., 2010. Análise da capacidade de uma central de atendimento de um centro de serviços compartilhados (CSC). Porto Alegre: Universidade Federal do Rio Grande do Sul.

SPIEGEL, M. R., 1972. Estatística - Coleção Schaum. São Paulo: McGraw-Hill.

TAKEDA, T. L., 2012. Proposta de aplicação de método quantitativo de previsão de vendas em uma indústria metal-mecânica. Joinville: Universidade do Estado de Santa Catarina.

YONAMINE, J. S. G., 2006. O setor de call centers e métodos quantitativos: uma aplicação da simulação. Rio de Janeiro: COPPEAD/UFRJ. 